\title{
The outflow of polar water through the Arctic Archipelago and the oceanographic conditions in Baffin Bay
}

\author{
BERT RUDELS
}

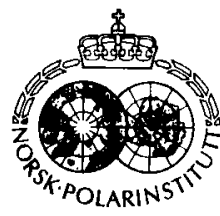

\begin{abstract}
Rudels, B. 1986: The outflow of polar water through the Arctic Archipelago and the oceanographic conditions in Baffin Bay. Polar Research 4 n.s., 161-180.

The transports of mass, heat, and salt through the Arctic Archipelago are estimated by two different approaches. First: A baroclinic, rotationally controlled flow is assumed through the Arctic Archipelago and the Davis Strait, with all passages transporting at maximum capacity. Second: Mass, salt, and energy balances are considered for the upper 'cold core' in Baffin Bay. The mass transport in the first case decreases and in the second case increases with increasing salinity in the Beaufort Sea. It is thus possible to determine a salinity at which both approaches give the same mass transport. The outflow in the upper layers is estimated at $0.7 \cdot 10^{9} \mathrm{~kg} \mathrm{~s}^{-1}$ with a salinity of 32.9 . The amount of water from the Polar Ocean entering the deeper (Atlantic) layer in Baffin Bay is more difficult to assess. A tentative value of $0.3 \cdot 10^{9} \mathrm{~kg} \mathrm{~s}^{-1}$ with a salinity of 34.3 is proposed.
\end{abstract}

Bert Rudels, Norwegian Polar Research Institute, N-1330 Oslo Lufthavn, Norway; July 1985 (revised May 1986)

The Polar Ocean (Vowinckel \& Orvig 1970) has four main connections with the world oceans. Through the Bering Strait it communicates with the Pacific, while the remaining passages, the Arctic Archipelago, the Fram Strait, and the Barents Sea, control the exchanges with the Atlantic. Most of the oceanographic work has concentrated on the Bering Strait and in the last couple of years especially on the Fram Strait. However, the fact that the other passages have been somewhat overshadowed does not imply that they are less important. A substantial part of the Atlantic inflow to the Polar Ocean may take place over the Barents Sea and about half of the polar surface water, which discharges into the Atlantic, passes through the archipelago (Stigebrandt 1981). The flow through the archipelago is unidirectional, as in the Bering Strait. This is in contradistinction to the other passages where exchanges in both directions take place.

In the present work we shall in section 1 briefly review the geographic, topographic, and oceanographic features of the archipelago and Baffin Bay and present some existing estimates of the exchanges. In section 2 we try to determine the transports by a dynamical method, while in section 3 mass, heat, and salt balances in Baffin Bay are used to obtain the exchanges. The interaction between the upper and lower layers in Baffin Bay is considered in section 4 , and in section 5 the deeper circulation is discussed. Our results are then summarized in section 6 .

\section{Background}

The Amerasian basin (the Beaufort Sea) has direct communication with the Atlantic through the passages in the Arctic Archipelago entering Baffin Bay. The three sounds, Lancaster Sound, Jones Sound and the Nares Strait, are long, shallow and except for Lancaster Sound rather narrow $(55,12,18 \mathrm{~km})$. Baffin Bay is a large, elongated bay between Greenland and the Ellesmere, Devon, and Baffin Islands. It has an area of $0.44 \cdot 10^{12} \mathrm{~m}^{2}$. Its main entrance is to the south through the $640 \mathrm{~m}$ deep and $300 \mathrm{~km}$ broad Davis Strait connecting to the Labrador Sea. The greater part of the bay is deeper than $500 \mathrm{~m}$ and in the central depression the depth is more than $2400 \mathrm{~m}$ (Fig. 1).

The main hydrographic features may be summarized briefly (Bailey 1957; Muench 1971). Water enters the Baffin Bay both from the north and the south, while practically the entire outflow occurs through the Davis Strait. The overall circulation is cyclonic. The West Greenland Current enters through the Davis Strait and follows the 


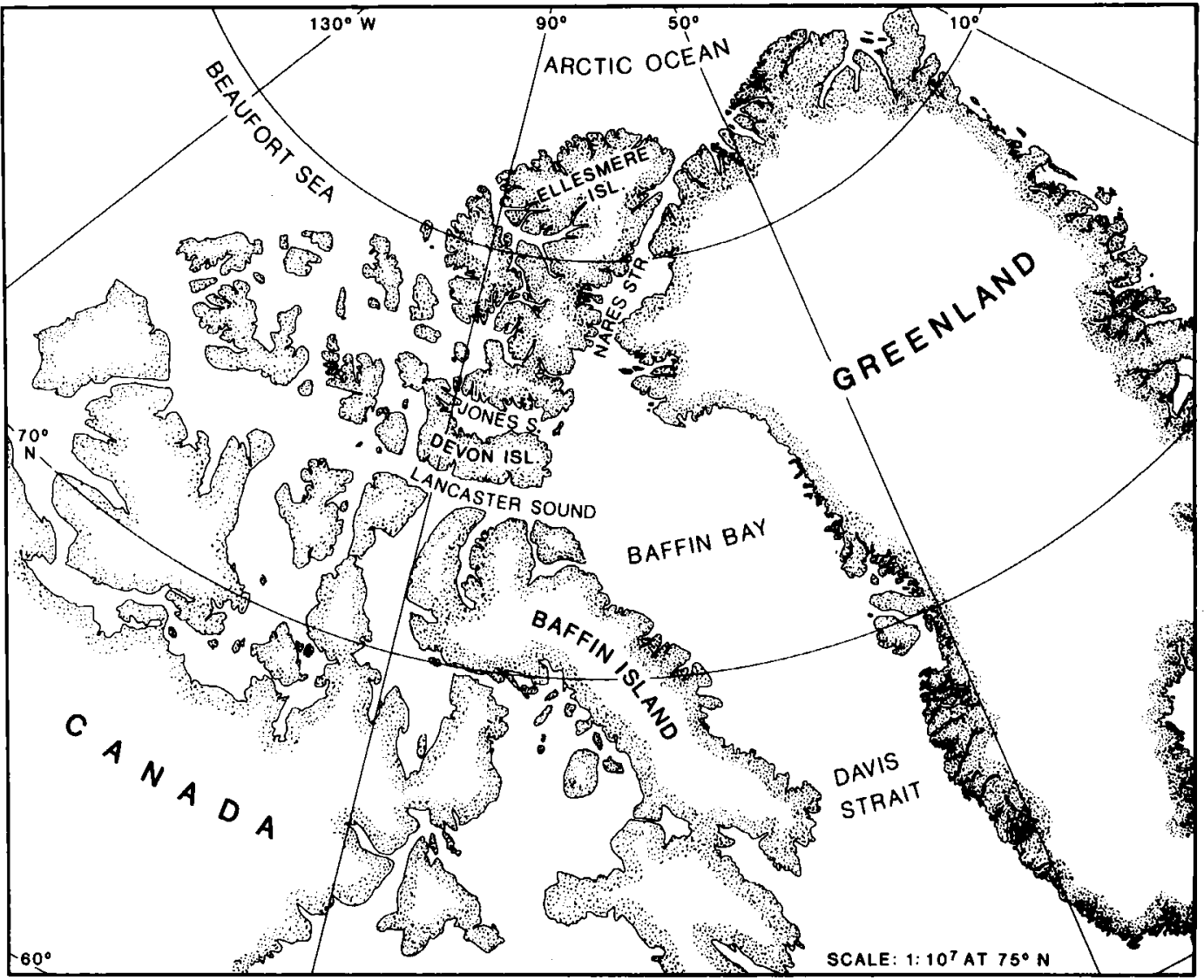

Fig. 1. Map of the Arctic Archipelago and Baffin Bay.

west coast of Greenland to the north. There it is augmented by the arctic inflow through the above mentioned straits, and the water returns to the south along the east coast of Baffin Island as the Baffin current exiting into the Labrador Sea.

Three different water masses may be distinguished in Baffin Bay (Fig. 2a, b). In the upper $200 \mathrm{~m}$ a cold core layer is encountered. Its temperature is -1.6 (Tchernia 1979) and the salinity is about 33.7. Baffin Bay is ice covered during the winter and a large, annually varying ice production is responsible for the $\theta-S$ characteristics of the cold core, which is commonly believed to be created in Baffin Bay (Tchernia 1979). In the summer a low saline (30-32) warmer layer (2$5^{\circ} \mathrm{C}$ ) is formed at the surface due to heating and ice melt.

The winter convection appears to be limited to the upper $200-250 \mathrm{~m}$. Further down the temperature increases and a maximum is found at about $500 \mathrm{~m}$. The temperature of the maximum depends upon location and ranges between 0.5 and $1.5^{\circ} \mathrm{C}$. Due to the shallowness of the northern passages only waters from the polar mixed layer and the pycnocline enter Baffin Bay, and the positive temperatures result from an inflow of Atlantic water through the Davis Strait. This Atlantic inflow probably becomes much diluted by water of arctic origin in the interior of Baffin Bay (see discussion in section 5).

The temperature then decreases downwards until below $1800 \mathrm{~m}$ it attains the constant value $-0.4^{\circ} \mathrm{C}$ of the bottom water. The salinity remains constant or perhaps shows a slight decrease to 34.44. The origin of the deep and bottom waters is subject to some controversy. The older view advanced by Sverdrup et al. (1942) is that the bottom water is formed by mixing Baffin Bay surface water, which has become cold and saline through ice formation, with Labrador Sea water. An alternative origin has been proposed by Bailey, who suggests that the abyssal water enters, 
a

SMITHS SOUND

TEMPERATURE 'C, BAFFin Bay

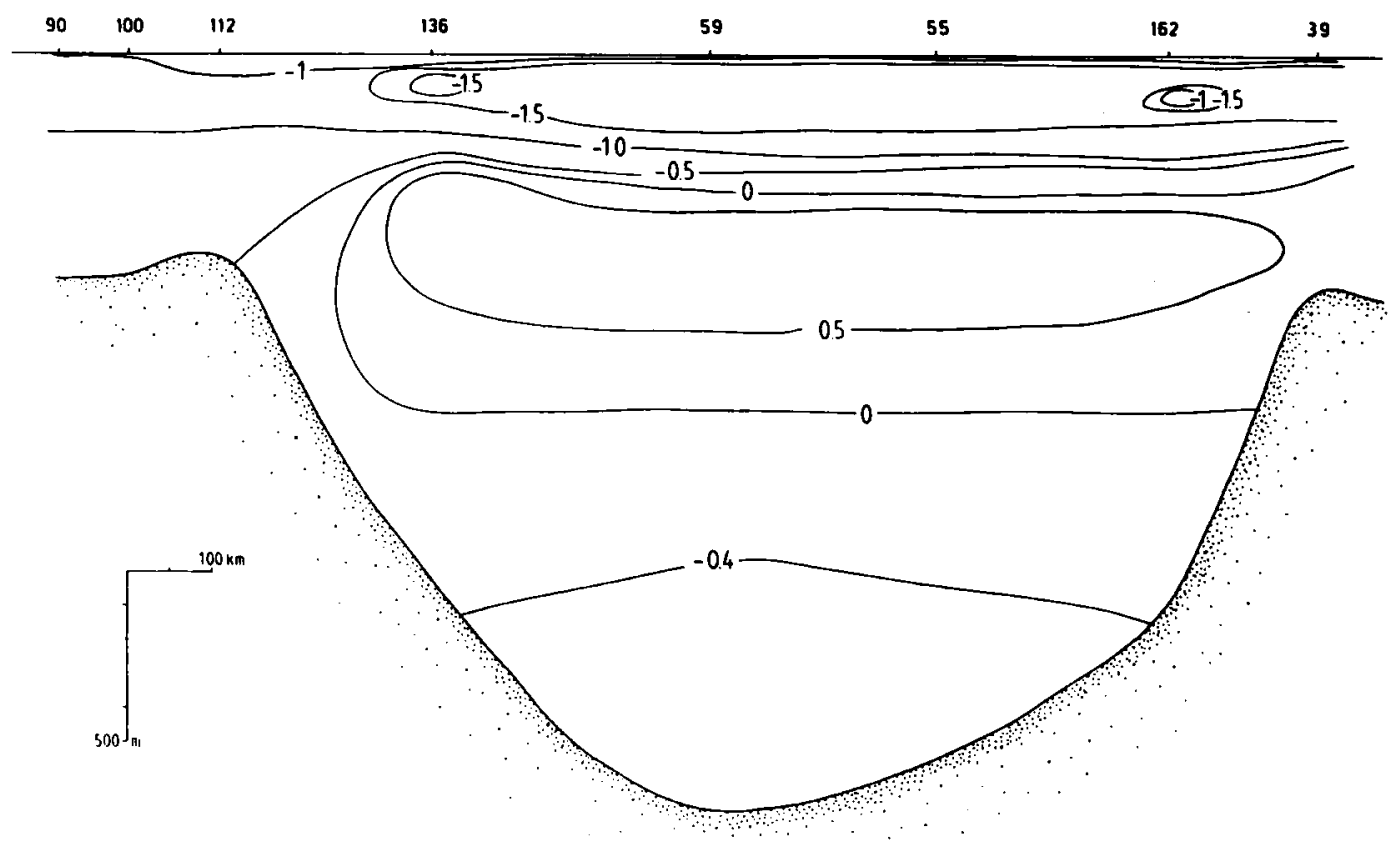

b

SMITHS SOUND

SALINITY, BAFFIN BAY

DAVIS STRAIT
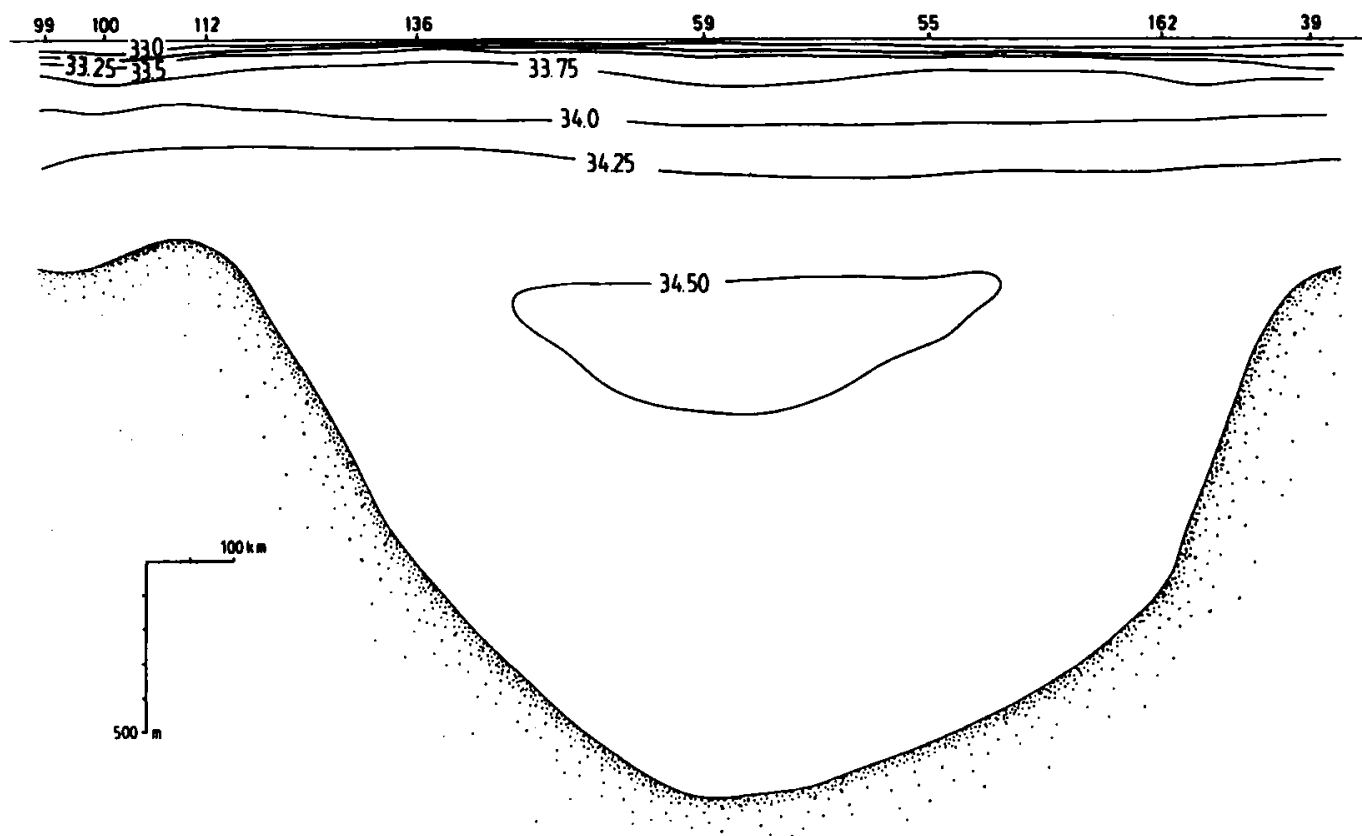

Fig. 2a, b. North-south section of temperature and salinity in Baffin Bay from Smith Sound to the Davis Strait. Data taken from Riis-Carstensen 1936. (Low-saline warm surface water not shown.) 


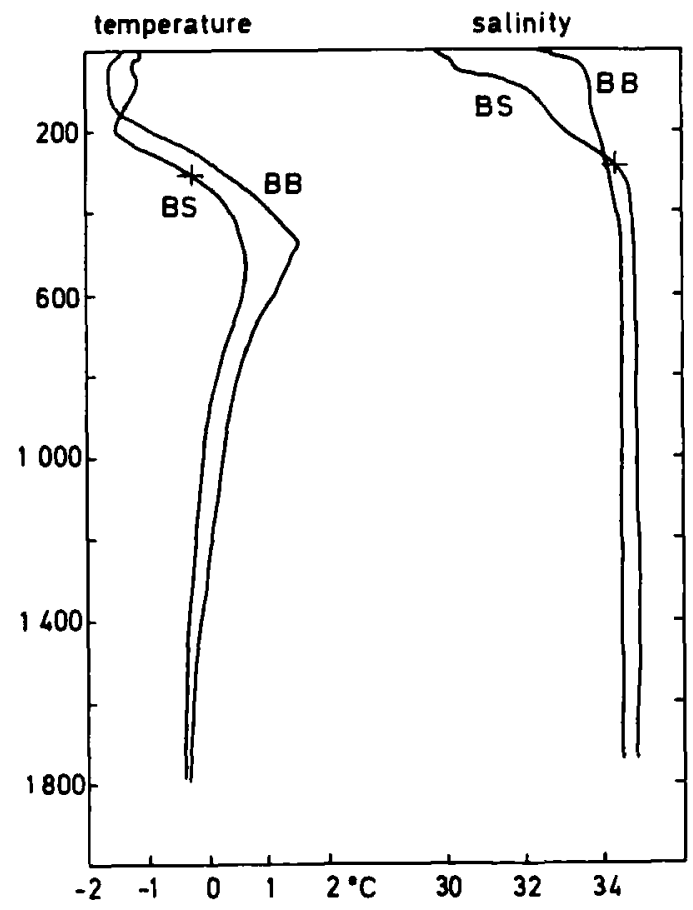

Fig. 3. Temperature and salinity profiles from the Beaufort Sca (BS) and Baffin Bay (BB). The level where the temperature and salinity in BS equal those of the bottom water in BB is shown (taken from Coachman \& Aagaard 1974).

perhaps intermittently, from the north. This is based upon observations of $\theta-S$ characteristics, which are the same for the Baffin Bay bottom water and the water found in the Beaufort and Lincoln seas at the 250-300 $\mathrm{m}$ level (Fig. 3). We shall return to these questions in section 5 .

The estimates of the outflow from the Polar Ocean through the archipelago differ considerably and range from 0.7 to more than $3 \cdot 10^{9} \mathrm{~kg}$ $\mathbf{s}^{-1}$. These figures have mainly been obtained from dynamical computations based upon hydrographic sections taken in the three northern straits as well as across Baffin Bay and in the Davis Strait. Most of the earlier investigations are presented or summarized in Bailey (1957), Coachman \& Aagaard (1974), Collin \& Dunbar (1963), Kiilerich (1939), and Muench (1971).

The transports computed in the individual channels vary considerably with time. This is probably die to the narrowness of the passages, which allows wind induced Ekman transports across the channels to alter the baroclinic density field. If the outflows in the individual straits are integrated into a larger transport system, it may be that variations in different straits compensate each other and the total outflow remains more constant. Should this be the case, measurements in all channels at the same time are necessary to obtain an estimate which reflects the mean conditions.

A more practical way to reach the same goal might be to concentrate the observations on the Davis Strait since the arctic outflow eventually has to enter the Labrador Sea.

The notorious difficulty connected with the unknown barotropic velocity component has only in a few instances been remedied by direct current measurements (Sadler 1976). Another uncertainty in the estimates is that they are mostly based upon summer observations, which may not be representative for mean annual conditions.

\section{The outflow of polar surface water}

The surface layer in the Beaufort Sea is lighter than in Baffin Bay (Fig. 3). Muench (1971) estimates the difference in steric heights between the two seas to be $0.30 \mathrm{db}$, with respect to the $250 \mathrm{db}$ level. Assuming that we have pressure compensation in the deeper layers, this difference creates a pressure gradient in the surface layer from the Beaufort Sea towards Baffin Bay, which may be instrumental in driving the flow through the archipelago.

The induced flow could be balanced by friction, as in the Bering Strait, or a primarily geostrophical balance may prevail. In contrast to the shallow Bering Strait these deeper channels have strong stratifications, and the corresponding vertical shear may result in weak flows and small frictional effects close to the bottom.

In the following discussion we find that the outflow velocity becomes zero at a depth less than the bottom depth, and the effects of bottom friction are therefore neglected. The horizontal transfer of momentum may be of importance in the narrower straits as it is in the Bering Strait (Coachman \& Aagaard 1966). Having no way of estimating its magnitude, we choose to ignore it altogether.

We shall adopt an approach similar to the one used by Stigebrandt (1981) and assume that the outflow is wedge-shaped and attached to the shore at its right hand side. To use a formulation based upon rotational control it is a necessary condition that the passages are broad enough for the upper 
layer to reach the surface and utilize the full flow capacity. The Rossby radius used is given by $\left(\frac{g \Delta \rho H^{\prime}}{\rho}\right)^{\prime} f^{-1}$ and its maximum value with $H^{\prime}=$ $150 \mathrm{~m}, \Delta \rho=0.0014 \mathrm{~g} \mathrm{~cm}^{-3}$ and $f=1.41 \cdot 10^{-4} \mathrm{~s}^{-1}$ becomes about $10 \mathrm{~km}$. This is sufficiently small to make the Lancaster Sound transport with full capacity, while the situation is more touch and go for the other passages. The separation of the $200 \mathrm{~m}$ isobath in the Robeson-Kennedy channel (Nares Strait) is $7-8 \mathrm{~km}$, and in the shallower Jones Sound a corresponding value would perhaps be less than $5 \mathrm{~km}$. These channels cannot utilize the full capacity, and the transports there would probably be more affected by the transfer of horizontal momentum, which also acts to decrease the transports.

Stigebrandt (1981) in his comprehensive model of the Polar Ocean considered the combined flow through the three outlets to be equivalent to the transport through $\gamma=1.3$ effective sounds. In the estimates presented above it seems that $\gamma=2$ would be a more appropriate value. We have chosen to use $\gamma=1.3$ to be able to compare our results with those obtained by Stigebrandt. Trial calculations with $\gamma=2.0$ were also run.

We then assume that the flow is geostrophic and passes through $\gamma$ effective sounds in the archipelago. In a two layer system the maximum baroclinic transport is controlled by the density differences between the water masses and the depth of the upper layer. By observing the conditions in the Beaufort Sea, where the temperatures and salinities may be closer to a climatological equilibrium than in the straits, it would be possible to determine a mean, geostrophically balanced flow through the archipelago. Stigebrandt assumes that the underlying layer has the density of the Atlantic water in all passages, and that the depth of the upper layers is given by the upper layer depth observed in the interior of the Polar Ocean. The geostrophic flow is then given by

$M=\frac{\gamma g \Delta \rho H_{1}^{2}}{2 \rho f}$ $\gamma=1.3$

However, a further complication arises, because this transport together with the inflow in the West Greenland Current must leave Baffin Bay through the Davis Strait. Such an increased flow can only take place through a single outlet if the depth and/or the density of the upper layer change. Otherwise the control section will move to the Davis Strait resulting in a lower transport from the Polar Ocean.

If the water in the upper layers is transformed in Baffin Bay as a result of winter cooling and ice formation and/or by mixing with the deeper layers, the depth and density of the upper layer will change. A state may then be reached where all sections are transporting at maximum capacity. We shall try to determine such a state.

Presently only the upper circulation will be considered and the Polar Ocean-Baffin BayAtlantic Ocean configuration is treated as a three reservoir system. The basins are separated by two sills, the outer (the Davis Strait) being the deeper

the Beaufort Sea

the Arctic Archipelago

Baffin Bay

Davis Strait

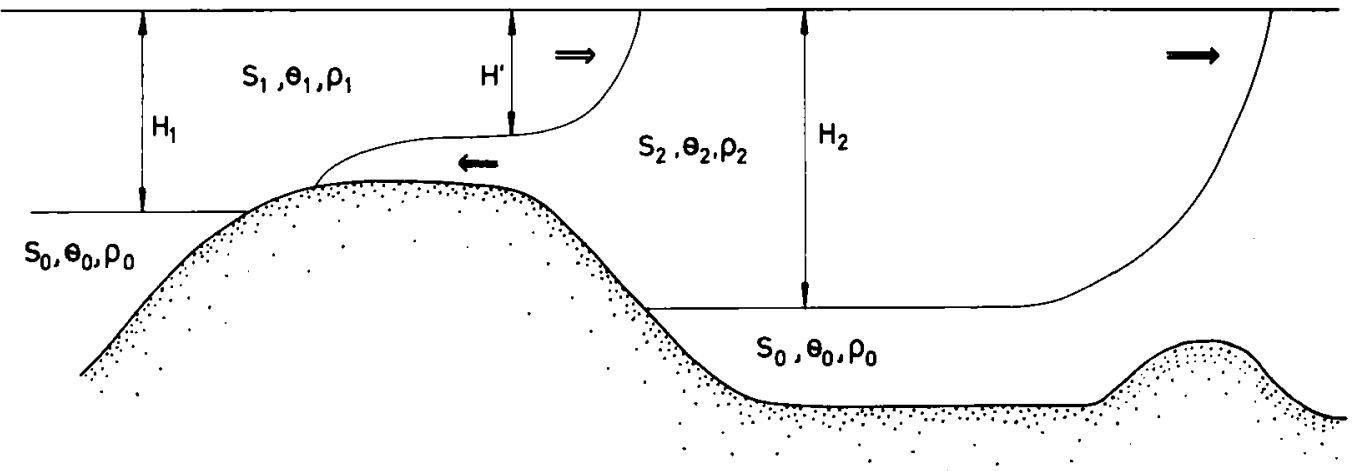

Fig. 4. Idealized three reservoir system representing the Beaufort Sea, Baffin Bay and the Labrador Sea (for explanations see text). 
(Fig. 4). In the Polar Ocean and Baffin Bay we have two layer stratifications with the densities $\rho_{1}, \rho_{2}$ and depths $H_{1}, H_{2}$ in the upper layers, while lower the Atlantic layer is taken to be homogeneous. The Atlantic water communicates over the outer sill, and its density $\rho_{0}$ is assumed to be the density of the lower layer in Baffin Bay. Since the Polar Ocean communicates with the Atlantic also through the Fram Strait and over the Greenland-Iceland-Scotland ridges with a sill depth of $600-700 \mathrm{~m}$, we take the density of the lower layer in the Polar Ocean to be the same as that of the Atlantic layer in Baffin Bay and the Labrador Sea. This is evidently an oversimplification, but since water of the appropriate density is present beneath the surface layer, it is perhaps not a considerably graver one than to approximate the stratification in the Beaufort Sea and its thick pycnocline (Fig. 3) with a two layer system. A different choice of the density in the Polar Ocean would not substantially affect the following treatment.

Briefly, we will balance the hydrostatic pressure of the water columns in the different basins, and assume that pressure compensation occurs in the lower Atlantic layer. A reason for this is that both in- and outflows take place in the Fram Strait and over the southern ridges at shallower levels than the sill depth in the Davis Strait, which suggests that no prominent pressure gradient exists between the Polar Ocean and the Atlantic at that level. If pressure compensation is accomplished between the Atlantic and the Polar Oceans, it will also hold in the lower layers between the Polar Ocean and Baffin Bay (provided that we are) above the Davis Strait sill depth. In the deeper layers no such compensation exists, and the Baffin Bay deep water is much lighter than the water at corresponding depth in the Polar Ocean.

To find the transports we simply move the different water columns into contact in the strait and compute the vertical shear resulting from the density field. The lighter fluid then flows as a wedge with its greatest depth close to the coast at the right hand side. The denser layer reaches the surface at the far side of the strait and is motionless. At the depth $H^{\prime}$, where pressure compensation occurs, the denser fluid undercuts the lighter and fills the lower part of the strait. Such intrusions of Baffin Bay surface water have been observed close to the bottom in the northern channels (Collin \& Dunbar 1963; Muench 1971). Due to bottom friction the motions in these intrusions are expected to be weak, and the assumption of no motion in the lower layer introduced above should hold. Since the depth of the lighter fluid $H^{\prime}$, which controls the transport, is the same as the depth at which pressure compensation takes place, it is easier to perceive what is going on by looking at the conditions along the axes of the basins (Fig. 4 and Figs. 7, 8).

We have made the presupposition that pressure compensation holds in the deeper layers and we know that the surface layer is denser in Baffin Bay than in the Beaufort Sea. The depth $H^{\prime}$, with no pressure gradient in the northern strait, cannot be the depth of the surface layer in Baffin Bay since the geostrophic control in the Davis Strait would not allow the increased flow to leave Baffin Bay rapidly enough. Baffin Bay would be filled up and react in two ways: Firstly by increasing the depth of the surface layer and allowing a higher transport out of the Davis Strait; secondly by decreasing the difference in steric heights between the Beaufort Sea and Baffin Bay and thus decreasing the polar outflow. If there were no pressure compensation in the first, northern

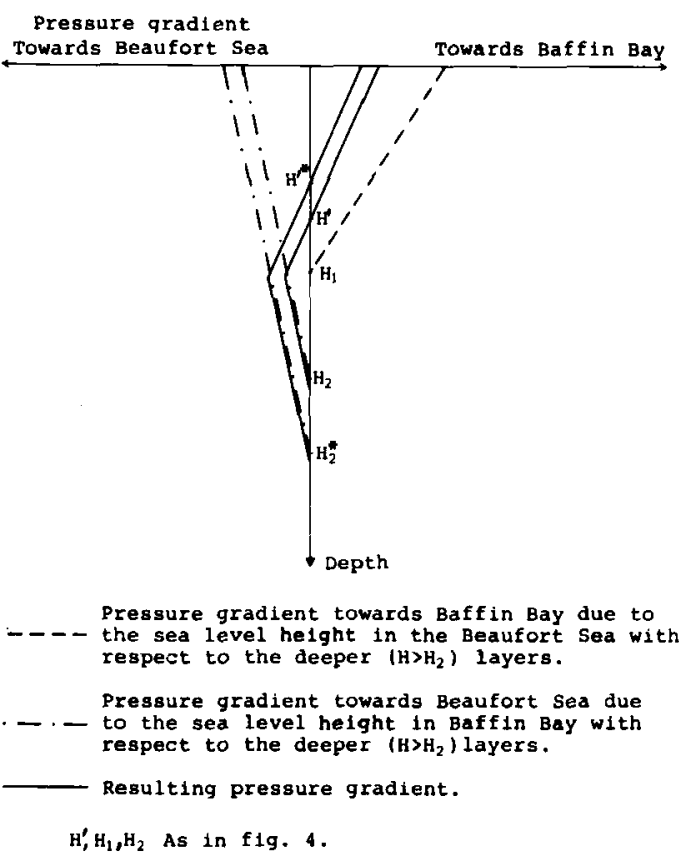

Fig. 5. Depth of the upper layer in the Archipelago: $H^{\prime}$, and in Baffin Bay: $H_{2}$, as a function of the salinity in the Beaufort Sea. Broken lines indicate values obtained when an entrainment of $0.12,10^{4} \mathrm{~kg} \mathrm{~s}^{-1}$ from the lower layer is added. 
strait and the situation were akin to the one in the Bering Strait, a flow of both surface and deep water into the Baffin Bay would then occur through the archipelago as well as through the Davis Strait, changing the sea surface and interface levels in such a way that pressure compensation arises in the northern strait. All this is a consequence of the deep pressure compensation due to the connection through the Fram Strait.

There are then two levels with vanishing pressure gradients: At $\mathrm{H}_{2}$, the depth of the denser surface layer in the Baffin Bay and at $H^{\prime}$, the depth of the lighter surface layer in the Arctic Archipelago. This can be written as

$g \rho_{1}\left(H_{1}+\eta\right)+g \rho_{0}\left(H_{2}-H_{1}\right)=g \rho_{2} H_{2}$

and

$g \rho_{1}\left(H^{\prime}+\eta\right)=g \rho_{2} H^{\prime}$

where $\eta$ is the difference in steric height between the Beaufort Sea and Baffin Bay. Combining the two equations one obtains

$H^{\prime}=H_{1} \frac{\left(\rho_{0}-\rho_{1}\right)}{\left(\rho_{2}-\rho_{1}\right)}-H_{2} \frac{\left(\rho_{0}-\rho_{2}\right)}{\left(\rho_{2}-\rho_{1}\right)}$

The transport through the archipelago is controlled by the conditions in the strait and the

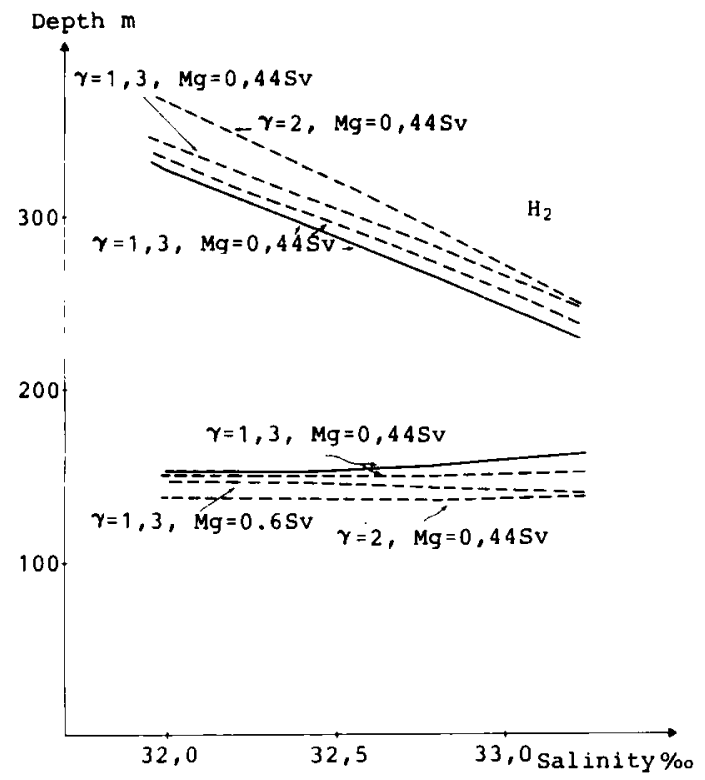

Fig. 6. The transport $M_{1}$ through the Arctic Archipelago as a function of the salinity in the Beaufort Sca. (Broken lines as in Fig. 6.) geostrophical transport becomes

$M_{1}=\frac{\gamma g\left(\rho_{2}-\rho_{1}\right) H^{\prime 2}}{2 \rho f}$

The transport out of the Davis Strait is given by

$M_{2}=\frac{g\left(\rho_{0}-\rho_{2}\right) H_{2}^{2}}{2 \rho f}$

We require mass balance in the surface layer of Baffin Bay. In addition to the polar inflow we also have the inflow $M_{g}$ through the West Greenland Current and a possible entrainment $w_{e} A$ of water from the deeper Atlantic layer. We then have

$M_{2}=M_{1}+M_{g}+w_{e} A$

$w_{e}=$ entrainment velocity, $A=$ Area of Baffin Bay

Run-off and precipitation have been ignored, and we have assumed that the convection arising from cooling and ice formation homogenizes the surface layer and gives it its characteristics; $\theta_{2}=1.6^{\circ} \mathrm{C}$ and $S_{2}=33.7$, but it does not allow any surface water to sink deeper into the column than the cold core. The density of the cold core thus becomes $\rho_{2}=1.02712 \mathrm{~g} \mathrm{~cm}^{-3}$. For the polar inflow we choose $\theta_{1}=-1.0^{\circ} \mathrm{C}$, but allow the salinity to vary between 32.0 and 33.2 since Fig. 2 may represent summer conditions with a large component of melt water. As $H_{1}$ we take the depth where the density of the Beaufort Sea becomes greater than the density at the corresponding depth in Baffin Bay, which gives $H_{1}=$ $200 \mathrm{~m}$. If the contributions from the West Greenland Current and from entrainment were known it would be possible to determine $H^{\prime}$ and $H_{2}$ and thus compute $M_{1}$ and $M_{2}$.

To estimate $M_{g}$ we need to know its density and maximum depth as it enters through the Davis Strait assuming that the same dynamics holds as for the outflow. The section reproduced by Defant $(1961$, p. 666) indicates that on average the values $\theta_{g}=4.0^{\circ} \mathrm{C}$ and $S_{g}=33.2$ might be reasonable, giving an average density of $\rho_{g}=1.02635 \mathrm{~g} \mathrm{~cm}^{-3}$. The maximum depth of the surface layer is about $H_{g}=100$. The transport in the upper layers of the West Greenland Current then becomes

$M_{g}=\frac{g\left(\rho_{0}-\rho_{2}\right) H_{g}^{2}}{2 \rho f}=0.45 .10^{\mathrm{g}} \mathrm{kg} \mathrm{s}^{-1}$

This gives the transport relative to the Atlantic layer. Since the inflow of Atlantic water is prob- 
Table 1. Depth $\mathrm{H}_{2}$ of the cold core in Baffin Bay for different assumed salinities in the Beaufort Sea. a) $0.12 .10^{3} \mathrm{~kg} \mathrm{~s}^{-1} \mathrm{entrained}$ from below, b) no entrainment.

\begin{tabular}{lllllll}
\hline & & \multicolumn{2}{c}{$\mathrm{H}_{2} \mathrm{~m}$} & $\mathrm{H}$ & & $\mathrm{H}_{2} \mathrm{~m}$ \\
$\mathrm{~S}$ & $\mathrm{a}$ & $\mathrm{b}$ & $\mathrm{a}$ & $\mathrm{b}$ & $\mathrm{a}$ & $\mathrm{b}$ \\
\hline 32.0 & 333 & 327 & 367 & 361 & 342 & 335 \\
32.4 & 303 & 296 & 330 & 324 & 312 & 305 \\
32.8 & 272 & 264 & 292 & 286 & 282 & 275 \\
33.2 & 239 & 231 & 251 & 245 & 249 & 241 \\
& $\gamma=1.3$ & & $\gamma=2$ & $\gamma=1.3$ & $\mathbf{M}_{\mathrm{B}}=0.6 .10^{9} \mathrm{~kg} \mathrm{~s}^{-1}$ \\
\hline
\end{tabular}

ably weak (section 5), its motion will not greatly increase this estimate. Introducing 2.3 into 2.4 and using $2.4,2.5$, and 2.7 in 2.6 gives

$$
\begin{gathered}
\frac{g\left(\rho_{0}-\rho_{2}\right) H_{2}^{2}}{2 \rho f}=\frac{\rho g\left(\rho_{2}-\rho_{1}\right)}{2 \rho f}\left(\frac{H_{1}\left(\rho_{0}-\rho_{2}\right)}{\left(\rho_{2}-\rho_{1}\right)}\right. \\
\left.-\frac{H_{2}\left(\rho_{0}-\rho_{2}\right)}{\left(\rho_{2}-\rho_{1}\right)}\right)^{2}+\frac{g\left(\rho_{0}-\rho_{2}\right) H_{g}{ }^{2}}{2 \rho f}+w_{e} A
\end{gathered}
$$

Solving for $\mathrm{H}_{2}$ we then get

$$
\begin{aligned}
& H_{2}=\frac{K_{1} H_{1}}{K_{2}} \pm\left(\frac{K_{1}{ }^{2} H_{1}^{2}}{K_{2}^{2}}+\frac{K_{1}{ }^{2} H_{1}^{2}}{\gamma\left(\rho_{1} \rho_{2}\right) K_{2}}\right. \\
& \left.+\frac{\left(\rho_{2}-\rho_{1}\right)\left(\rho_{0}-\rho_{\mathrm{g}}\right) H_{\mathrm{g}}^{2}}{\left(\rho_{1}-\rho_{2}\right) K_{2}}+\frac{2 \rho f\left(\rho_{2}-\rho_{1}\right)}{g K_{2}\left(\rho_{0}-\rho_{2}\right)} w_{e} A\right)^{\prime} \\
& K_{1}=\gamma\left(\rho_{0}-\rho_{1}\right) \\
& K_{2}=\left(\rho_{2}-\rho_{1}\right)-\gamma\left(\rho_{0}-\rho_{2}\right)
\end{aligned}
$$

where the smallest positive root has been used.

We shall determine $\mathrm{H}_{2}$ and $\mathrm{H}^{\prime}$ for salinities $S_{1}: 32.0,32.4,32.8,33.8$ with the corresponding densities $\rho_{1}: 1.02572,1.02605,1.02637,1.02669 \mathrm{~g}$ $\mathrm{cm}^{-3}$. For the Atlantic water we put $\theta_{0}=1.0^{\circ} \mathrm{C}$, $S_{0}=34.5$ giving the density $\rho_{0}=1.02764 \mathrm{~g} \mathrm{~cm}^{-3}$. $\rho$ is put to $1.0274 \mathrm{~g} \mathrm{~cm}^{-3}$. The entrainment is either ignored or the result obtained in section 4 is used.

The values of $H_{2}$ and $H^{1}$ are shown in Tables 1 and 2 and Fig. 5 for $\gamma=1.3$ and $\gamma=2$. For $\gamma=$ 1.3, two values of the East Greenland Current transport, $M_{g}$, have been used. The obtained transports from the Polar Ocean are presented in Table 3 and Fig. 6.

The resulting depths seem to be in an acceptable range. The section in Defant referred to above indicates a depth of the outflow through the Davis Strait of about $350 \mathrm{~m}$, if the -1.0 isoterm is taken as a demarcation value for the Baffin Bay surface water, which is close enough considering the approximations involved.

To find whether $H^{\prime}$ is reasonable is rather more difficult. However, on the section along Lancaster Sound presented by Collin \& Dunbar (1963) we may note the thicker, somewhat colder layer between the 33 and 34 isohalines to the east which represent the cold core layer. This layer could be present in the Barrow Strait below $150 \mathrm{~m}$, but the evidence is not conclusive from the section. Collin \& Dunbar also give the sill depth at the Barrow Strait to be $150 \mathrm{~m}$, which is perhaps a more tangible reason for limiting the arctic inflow to above this level.

The obtained transports are low but acceptable. The estimates presented by Collin \& Dunbar

\begin{tabular}{|c|c|c|c|c|c|c|}
\hline \multirow[b]{2}{*}{$\mathbf{S}$} & \multicolumn{2}{|c|}{$H^{\prime} m$} & \multicolumn{2}{|c|}{$H^{\prime} m$} & \multicolumn{2}{|c|}{$H^{\prime} m$} \\
\hline & a & b & $\mathbf{a}$ & b & a & b \\
\hline 32.0 & 151 & 153 & 138 & 140 & 147 & 150 \\
\hline 32.4 & 150 & 153 & 137 & 140 & 146 & 149 \\
\hline 32.8 & 150 & 156 & 136 & 140 & 143 & 148 \\
\hline \multirow[t]{2}{*}{33.2} & 153 & 163 & 138 & 148 & 141 & 150 \\
\hline & \multicolumn{2}{|c|}{$\begin{array}{l}\gamma=1.3 \\
\mathrm{M}_{\mathrm{g}}=0.44 \cdot 10^{9} \mathrm{~kg} \mathrm{~s}^{-1}\end{array}$} & \multicolumn{2}{|c|}{$\begin{array}{l}\gamma=2 \\
\mathrm{M}_{\mathrm{g}}=0.44 \cdot 10^{9} \mathrm{~kg} \mathrm{~s}^{-1}\end{array}$} & \multicolumn{2}{|c|}{$\begin{array}{l}\gamma=1.3 \\
\mathrm{M}_{\mathrm{g}}=0.6 .10^{9} \mathrm{~kg} \mathrm{~s}^{-1}\end{array}$} \\
\hline
\end{tabular}
(1963) for the transports through the Davis Strait give nearly $2.10^{9} \mathrm{~kg} \mathrm{~s}^{-1}$ for the outflow, and the inflow in the West Greenland Current is about

Table 2. Depth $\mathrm{H}^{\prime}$ of the upper layer in the Arctic Archipelago for different assumed salinities in the Beaufort Sea. a) $0.12,10^{4}$ $\mathrm{kg} \mathrm{s}^{-1}$ entrained from below, b) no entrainment. 
Table 3. Transport of Polar surface water $\mathbf{M}_{1}$ through the Arctic Archipelago for different assumed salinities in the Beaufort Sea. a) $0.12 \cdot 10^{9} \mathrm{~kg} \mathrm{~s}^{-1}$ entrained from below, b) no entrainment.

\begin{tabular}{|c|c|c|c|c|c|c|}
\hline & \multicolumn{2}{|c|}{$\mathbf{M}_{1}$} & \multicolumn{2}{|c|}{$\mathbf{M}_{1}$} & \multicolumn{2}{|c|}{$\mathbf{M}_{1}$} \\
\hline & a & $b$ & $\mathbf{a}$ & b & $\mathrm{a}$ & b \\
\hline 32.0 & 1.40 & 1.44 & 1.80 & 1.86 & 1.32 & 1.38 \\
\hline 32.4 & 1.06 & 1.10 & 1.36 & 1.42 & 1.00 & 1.04 \\
\hline 32.8 & 0.74 & 0.80 & 0.94 & 0.99 & 0.67 & 0.72 \\
\hline \multirow[t]{2}{*}{33.0} & 0.44 & 0.50 & 0.55 & 0.62 & 0.38 & 0.43 \\
\hline & \multicolumn{2}{|c|}{$\begin{array}{l}\gamma=1.3 \\
\mathbf{M}_{\mathrm{g}}=0.44 \cdot 10^{9} \mathrm{~kg} \mathrm{~s}^{-1}\end{array}$} & \multicolumn{2}{|c|}{$\begin{array}{l}\gamma=2 \\
\mathbf{M}_{\mathrm{g}}=0.44 .10^{9} \mathrm{~kg} \mathrm{~s}^{-1}\end{array}$} & \multicolumn{2}{|c|}{$\begin{array}{l}\gamma=1.3 \\
\mathrm{M}_{\mathrm{g}}=0.6 \cdot 10^{9} \mathrm{~kg} \mathrm{~s}^{-1}\end{array}$} \\
\hline
\end{tabular}

1. $10^{9} \mathrm{~kg} \mathrm{~s}^{-1}$. This is larger than the present values, but it is not clear if this also includes the transport in the deeper layers. Muench (1971) studies the transports through four sections in northern Baffin Bay and there obtains a southward flow in the Baffin Bay current of $2.3 .10^{9} \mathrm{~kg}$ $\mathrm{s}^{-1}$ and a much weaker West Greenland Current $\left(0.2 \cdot 10^{9} \mathrm{~kg} \mathrm{~s}^{-1}\right)$.

A choice of 32 as the salinity in the Beaufort Sea would then give a southward transport through the Davis Strait in agreement with most estimates. However, the corresponding salt transport is quite low compared with those given by Aagaard \& Greisman (1975) and Stigebrandt (1981) (see also Table 5). It should, therefore, be pointed out that there is no indication of water with salinity and density greater than the cold core being formed by brine rejection in the straits during winter (see the $\theta-S$ diagram presented by Muench (1971), Figs. 9, 12). This means that water which leaves the Beaufort Sea less dense than the cold core is still lighter than the core when it reaches Baffin Bay. Changes in salinity, which obviously occur during the winter, will alter the salinity of the water, but it still enters the surface layer in Baffin Bay. The total salt transport is probably not affected since the ice, even if it is landlocked in winter, breaks up in the warmer season and drifts with the water towards the east and Baffin Bay (Collin \& Dunbar 1963).

It is perhaps surprising that the effective depth $H^{\prime}$ is practically independent of $S_{1}$. This is probably due to the presence of the West Greenland Current. It masks the otherwise expected nonlinear behaviour (see Fig. 6 and Table 2) resulting from the non-linear variation of the transport out of the Davis Strait due to the decrease in $\mathrm{H}_{2}$, which is necessary to retain pressure compensation in the deeper layer. As the situation is now the changes in transports through the archipelago vary inversely with the changes in density in the upper layers of the Polar Ocean.
We may note that the system is stable to disturbances, as can be seen by examining the pressure gradients resulting from different stratifications. A deepening of the surface layer in Baffin Bay will reduce $H^{\prime}$ and thus lower the inflow from the Polar Ocean, while the outflow through the Davis Strait increases, removing the excess surface water, and the system is forced back to the state where all passages transport with maximum capacity (under the geostrophic constraint) (Fig. 7). Similarly, an increase in density of the Baffin Bay surface layer will result in an increased polar inflow and a decreased outflow

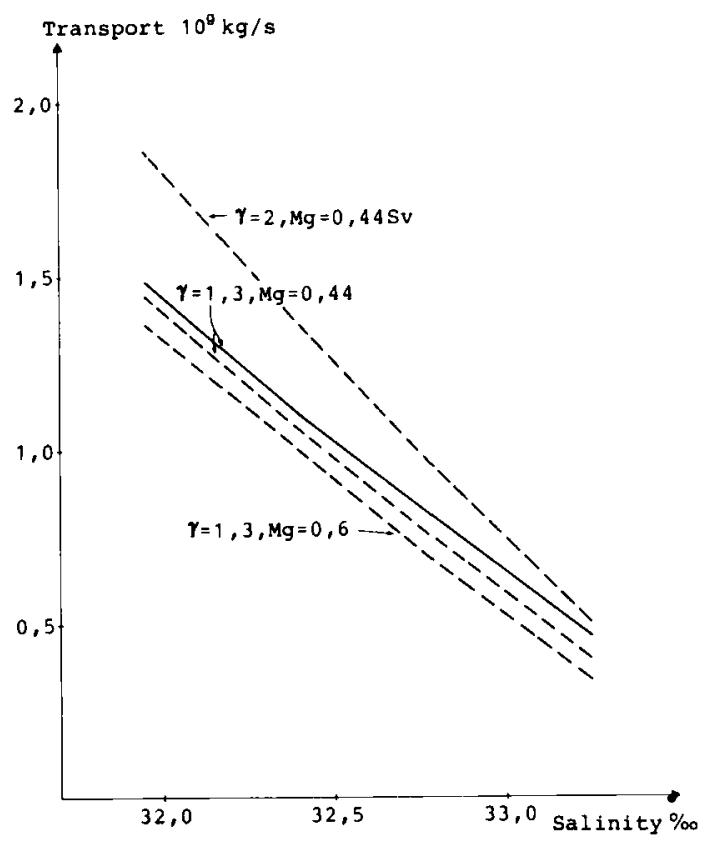

Fig. 7. The pressure gradients between the Beaufort Sea and Baffin Bay due to the differences in steric heights with respect to the deeper motionless layer. Asterisk $\left(^{*}\right)$ shows the effect of changes in depth $\mathrm{H}_{2}$ of the upper layer in Baffin Bay: A smaller inflow from the Arctic, $H^{\prime *}<H^{\prime}$, increased outflow through Davis Strait, $\mathrm{H}_{2}{ }^{*}>\mathrm{H}_{2}$. 

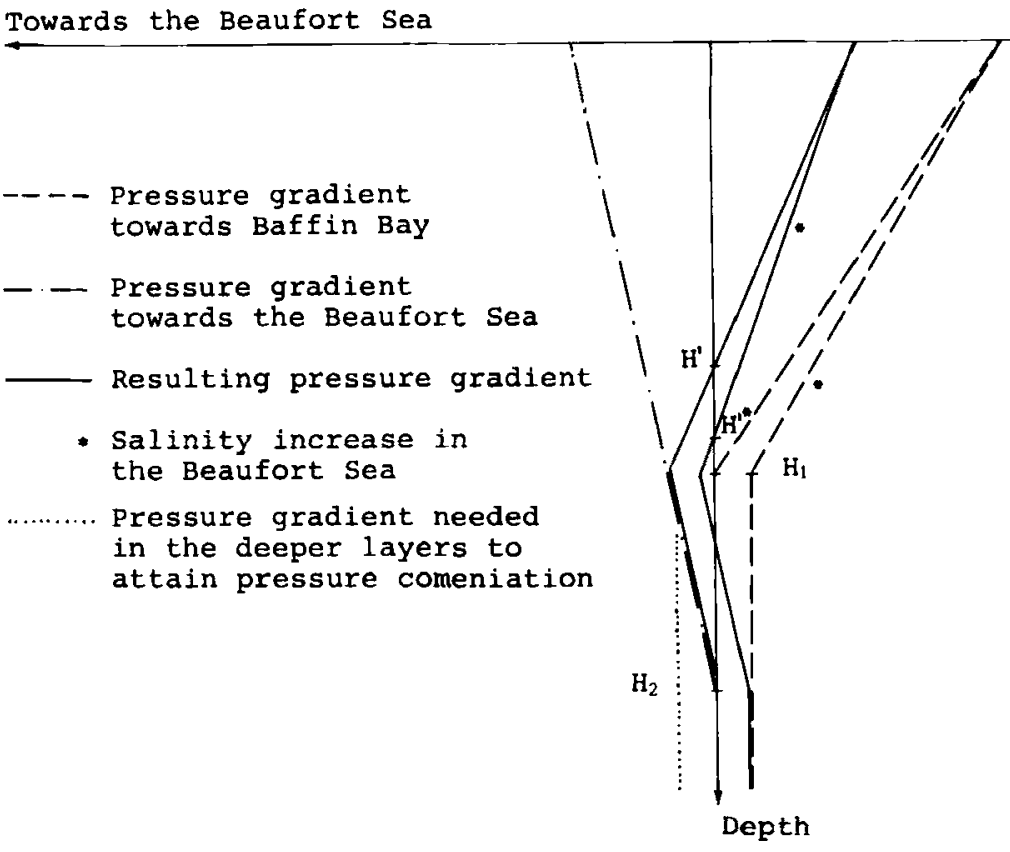

b

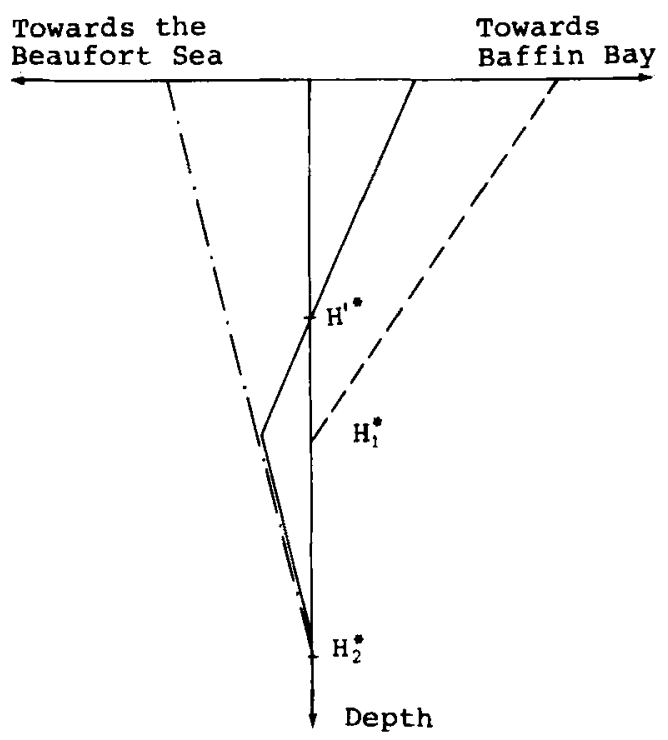

c

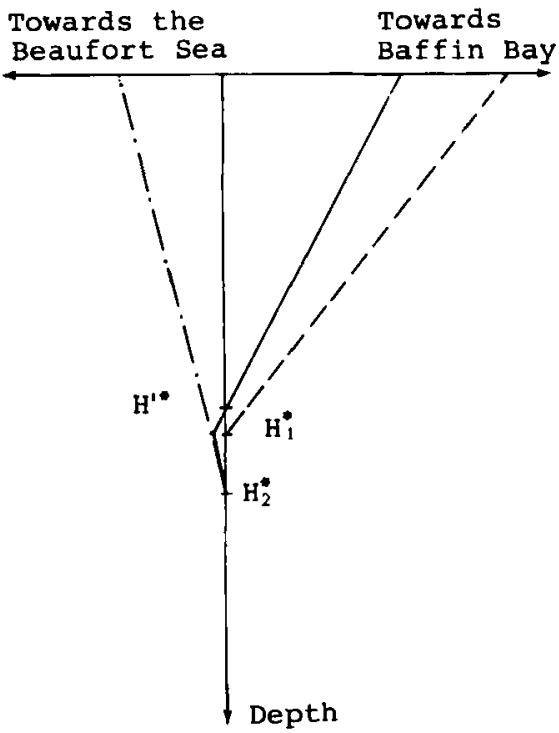

Fig. 8. Changes in the pressure gradients as the result of a varying salinity in the Beaufort Sea. Asterisk ( $\left.{ }^{*}\right)$ indicates the effect of a higher salinity in the Beaufort Sea. The pressure gradient in the deeper layer is compensated partly by lessening of the differences in steric heights (b) and partly by a decrease of the depth $\mathrm{H}_{2}$ in Baffin Bay (c). The partition between these two effects is given on the condition that all passages transport at maximum capacity. 
through the Davis Strait which will act to restore the initial density.

It is, however, noteworthy that an increased salinity in the upper layers of the Polar Ocean could drive a deeper inflow during the transition period when the system tries to regain pressure compensation in the deeper layers. This can only be done by decreasing the thickness of the upper layer in Baffin Bay. The inflow will go down due to the smaller density contrast in the archipelago, and the depth will approach a value fulfilling both pressure compensation and matching the in- and outflow. While this state is being attained there is a pressure gradient into Baffin Bay at deeper levels (Fig. 8), which may force a deep inflow.

However, a more likely driving force would be different atmospheric pressures over the Lincoln Sea and Baffin Bay, which could drive a deep inflow through the Nares Strait as suggested by Muench (1971).

We have found that outflow through the archipelago as a function of the salinity in the Beaufort Sea. To decide what value on the salinity (and transport) to use we shall try to obtain an independent estimate by looking at the mass, salt, and energy balance in the upper layers of Baffin Bay.

\section{Mass, salt, and heat balances in the upper layers of Baffin Bay}

The prominent cold core found in the upper layer has a characteristic temperature, $\theta=-1.6^{\circ} \mathrm{C}$, and salinity, $S_{2}=33.7$. The existence of the core indicates that all water with density less than that of the core will be affected by the surface processes in Baffin Bay during the winter. Lighter waters entering from the Beaufort Sea as well as through the Davis Strait will be transformed into cold core water. This homogenizing could, together with knowledge of the heat loss through the sea surface and a reasonable guess at the ice production, be used to estimate the inflow of surface water from the north and the south to Baffin Bay.

The yearly average heat loss $q$ through the sea surface in Baffin Bay is estimated at $-70 \mathrm{~W} \mathrm{~m}^{-2}$ (Bunker 1978 priv. comm.). The total heat loss then becomes $q A=Q\left(A=0.44 .10^{12} \mathrm{~m}^{2}\right.$ from above), and this loss must be met by cooling of the entering waters and by a net ice export. Since we are considering the annual mean energy loss, the heat, which is accumulated in the warm sur- face layer during summer, will not enter the balance. Some of this warm surface layer leaves through the Davis Strait, and if we estimate its depth to $30 \mathrm{~m}$ then $1 / 10$ of the outflow to the south during the summer consists of this warm water. The average yearly outflow is about $0.05 .10^{9} \mathrm{~kg} \mathrm{~s}^{-1}$ with a temperature of $3^{\circ} \mathrm{C}$. The exported heat will be partly compensated by a warmer inflow from the north in the summer. In the following these effects will be ignored.

The water in the upper $200 \mathrm{~m}$ of the Beaufort Sea is, as was noted above (section 2), less dense than the water at corresponding depths in Baffin Bay. The salinity of this upper layer ranges from 30 to 33.5. Following up the discussion in section 2 we assume that this water will remain less dense than the cold core water when it enters Baffin Bay, and the combined flow of ice and water will have the same average salinity as the upper layers in the Beaufort Sea.

As the mean salinity $S_{1}$ we use the same value as in section 2 and again we put the mean temperature $\theta_{1}$ equal to $-1.0^{\circ} \mathrm{C}$. While the salt transport is not altered by the formation and subsequent export of ice in the archipelago, this does not hold for the heat transport. It would, therefore, be more correct to use the temperature of the water as it enters Baffin Bay. This possible source of error is ignored as is the effect of melting of ice from the archipelago in Baffin Bay.

Water from the Polar Ocean denser than the cold core also passes through the straits. This water will sink beneath the core and so does not enter the energy balance of the surface layer. We shall return to the contribution of deep water in section 5 below.

The West Greenland Current carries warm, comparatively saline water into Baffin Bay. As above we assign the temperature $\theta_{g}=4^{\circ} \mathrm{C}$ and the salinity $S_{g}=33.2$ to the upper layers of the West Greenland Current as it passes through the Davis Strait.

Finally we assume that a net production of $z \mathrm{~m}$ of ice takes place during the year, which implies an ice export of $Z=z A t^{-1}$ from Baffin Bay ( $t=$ one year). For convenience the temperature of the ice $\theta_{i}$ is put equal to the temperature $\theta_{2}=$ -1.6 of the core, its salinity $S_{i}$ is assumed to be 5 , and its density is taken to be $1 \mathrm{~g} \mathrm{~cm}^{-3}$.

With the same notation as in section 2 the following conservation equations are obtained:

$M_{2} \theta_{2}+Z=M_{1}+M_{g}+w_{e} A$ 
mass balance

$M_{2}+Z \theta_{2}-Z L=M_{1} \theta_{1}+M_{g} \theta_{g}$

$+w_{e} A \theta_{0}+Q$

heat balance

$M_{2} S_{2}+Z S i=M_{1} S_{1}+M_{g} S_{g}+w_{e} A S_{0}$

salt balance.

$L$ is the latent heat of fusion, $w_{e} A$ is the entrainment from the lower layer, and the heat capacity of the water $C_{p}$ has been included into $\theta$. The left hand side represents the exports through the Davis Strait, while the right hand side gives all other contributions, negative as well as positive.

Using 3.1 in 3.2 and 3.3 and introducing $w_{e} A=$ $M_{0}$, we obtain

$\left(M_{1}+M_{g}+M_{0}-Z\right) \theta_{2}+Z\left(\theta_{2}-L\right)$

$=M_{1} \theta_{1}+M_{g} \theta_{g}+M_{0} \theta_{0}+Q$

$\left(M_{1}+M_{g}+M_{0}-Z\right) S_{2}+Z S_{i}=M_{1} S_{1}$

$+M_{g} S_{g}+M_{0} S_{0}$

which can be written as

$M_{1}\left(\theta_{1}-\theta_{2}\right)+M_{g}\left(\theta_{g}-\theta_{2}\right)+M_{0}\left(\theta_{0}-\theta_{2}\right)$

$=-(Q+Z L)$

$M_{1}\left(S_{1}-S_{2}\right)+M_{g}\left(S_{g}-S_{2}\right)+M_{0}\left(S_{0}-S_{2}\right)$

$=Z\left(S_{i}-S_{2}\right)$

We introduce the notation $\left(\theta_{1}-\theta_{2}\right)=\Delta \theta_{1}$ etc. and transfer the contributions from the lower layer to the right hand side since these are obtained from an independent consideration of the entrainment (see section 4 ). The equations then become

$$
\begin{aligned}
& M_{1} \Delta \theta_{1}+M_{g} \Delta \theta_{g}=-\left(Q+Z L+M_{0} \Delta \theta_{0}\right) \\
& M_{1} \Delta S_{1}+M_{g} \Delta S_{g}=Z \Delta S_{i}-M_{0} \Delta S_{0}
\end{aligned}
$$

solving for $M_{1}$ and $M_{g}$ respectively, we get

$$
\begin{aligned}
& M_{1}\left(\frac{\Delta \theta_{1}}{\Delta \theta_{g}}-\frac{\Delta S_{i}}{\Delta S_{g}}\right)=-\frac{Q}{\Delta \theta_{g}}-Z\left(\frac{L}{\Delta \theta_{g}}+\frac{\Delta S_{i}}{\Delta S_{g}}\right) \\
& -M_{0}\left(\frac{\Delta \theta_{0}}{\Delta \theta_{g}}-\frac{\Delta S_{0}}{\Delta S_{g}}\right) \\
& M_{g}\left(\frac{\Delta \theta_{g}}{\Delta \theta_{1}}-\frac{\Delta S_{g}}{\Delta S_{1}}\right)=-\frac{Q}{\Delta \theta_{1}}-Z\left(\frac{L}{\Delta \theta_{1}}+\frac{\Delta S_{i}}{\Delta S_{1}}\right) \\
& -M_{0}\left(\frac{\Delta \theta_{0}}{\Delta \theta_{1}}-\frac{\Delta S_{0}}{\Delta S_{1}}\right)
\end{aligned}
$$

With $\Delta \theta_{1}, \Delta S_{1}$ etc. known it is possible to determine how the contributions from the Polar Ocean a

Transport $10^{\mathrm{a}} \mathrm{kg} / \mathrm{s}$

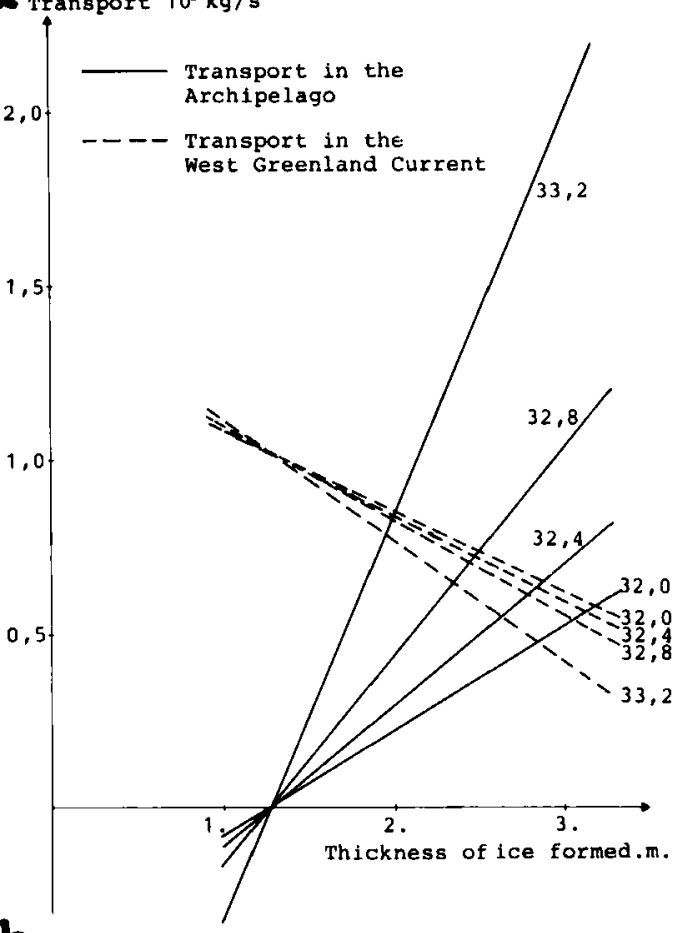

b.

Transport $10^{\circ} \mathrm{kg} / \mathrm{s}$

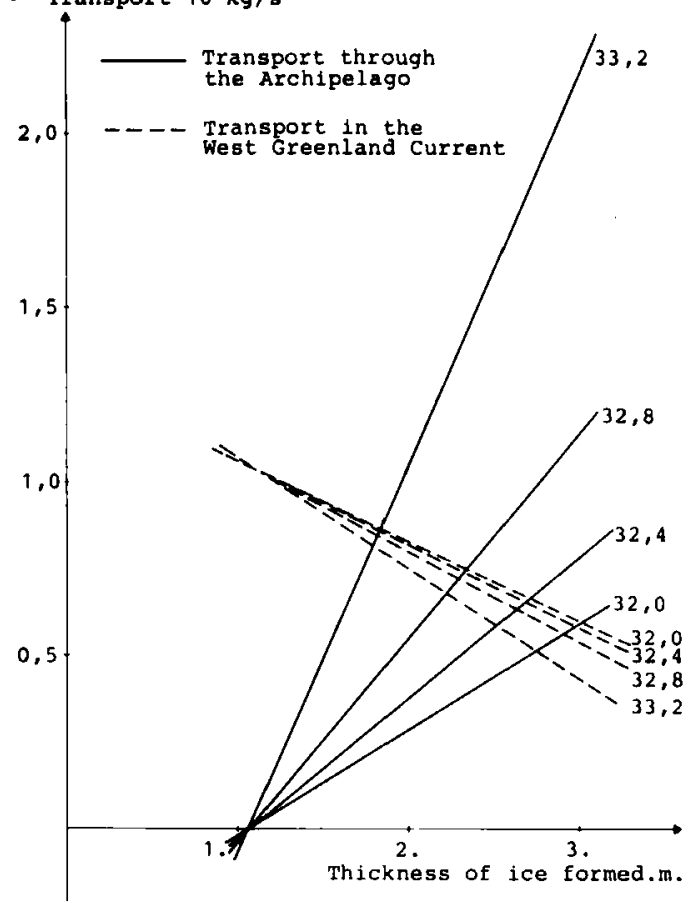

Fig. 9a,b. Transports through the Arctic Archipclago $M_{1}$ and in the West Greenland Current $M_{g}$ as functions of the amount of exported ice. a) $0.12 \cdot 10^{9} \mathrm{~kg} \mathrm{~s}^{-1}$ entrained from the lower layer. b) No entrainment. 
Table 4. Transports through the Arctic Archipelago. $\mathrm{M}_{1}$ and in the West Greenland Current $M_{g}$ as functions of the ice production in Baffin Bay for different assumed salinities in the Beaufort Sea. a) $0.12 \cdot 10^{9} \mathrm{~kg} \mathrm{~s}^{-1}$ entrained from lower layer, b) no entrainment.

\begin{tabular}{llrrrr}
\hline & & \multicolumn{2}{c}{$\mathrm{M}_{1} 10^{9} \mathrm{~kg} \mathrm{~s}^{-1}$} & \multicolumn{2}{c}{$\mathrm{M}_{\mathrm{g}} 10^{9} \mathrm{~kg} \mathrm{~s}^{-1}$} \\
$\mathrm{~S}$ & Ice production $\mathrm{m}$ & \multicolumn{1}{c}{$\mathrm{a}$} & \multicolumn{1}{c}{$\mathrm{b}$} & $\mathrm{a}$ & $\mathrm{b}$ \\
\hline 32.0 & 1 & -0.02 & -0.08 & 1.06 & 1.09 \\
32.0 & 2 & 0.28 & 0.22 & 0.83 & 0.85 \\
32.0 & 3 & 0.59 & 0.52 & 0.60 & 0.62 \\
32.4 & 1 & -0.03 & -0.11 & 1.06 & 1.09 \\
32.4 & 2 & 0.38 & 0.29 & 0.82 & 0.84 \\
32.4 & 3 & 0.78 & 0.70 & 0.58 & 0.59 \\
32.8 & 1 & -0.04 & -0.16 & 1.06 & 1.16 \\
32.8 & 2 & 0.55 & 0.43 & 0.80 & 0.82 \\
32.8 & 3 & 1.14 & 1.03 & 0.54 & 0.55 \\
33.2 & 1 & -0.07 & -0.32 & 1.07 & 1.12 \\
33.2 & 2 & 1.05 & 0.83 & 0.75 & 0.77 \\
33.2 & 3 & 2.17 & 1.99 & 0.43 & 0.42 \\
\hline
\end{tabular}

and the West Greenland Current vary with the heat exchange and the rate of ice production. Presently we consider the heat loss through the sea surface as given and concentrate on the effects of changes in ice production.

In Figs. 9a, $\mathrm{b}$ and Table 4 we display the contributions $M_{1}$ and $M_{g}$ as functions of the amount of ice formed, and in Fig. 10 the dependence of $M_{1}$ on the salinity in the Beaufort Sea is shown.

The inflow from the Polar Ocean is highly dependent upon the ice export. A greater ice export requires a larger inflow from the Polar Ocean, and at least $1 \mathrm{~m}$ of ice needs to be formed to give the observed north-south flow through the archipelago. Higher salinities in the Beaufort Sea also result in a larger inflow of polar water.

If the cooling should be less severe in some areas of Baffin Bay all surface water may not attain the salinity 33.7 during the winter. There are indications in some sections taken in the western parts of Baffin Bay that this may be the case (Riis-Carstensen 1936). If so, the effect would be the same as that of a slightly higher salinity of the inflow from the Polar Ocean, and we would underestimate the northern contribution somewhat.

It is interesting to note that the variation of the transport $M_{1}$, with respect to the salinity $S_{1}$, is opposite to what was found when a geostrophically balanced flow was considered explicitly (section 2). The reason for this is obvious. When the dynamics of the flow is considered, the salinity enters actively through the density giving a higher transport for a larger density contrast between the upper and lower layers. When the continuity requirements are used the salinity is passive. A certain amount of fresh water must be transformed into ice. If the salinity is high a larger flow is needed to supply the necessary amount of fresh water, since the maximum salinity the inflowing water may attain in Baffin Bay is given.

This difference in behaviour of the two approaches makes them complementary. The dynamical approach focuses on the assumed driving force, the difference in steric heights between the Beaufort Sea and Baffin Bay due to the positive fresh water balance in the upper layer, while the continuity approach supplies additional constraints of the Arctic which the actual flow must fulfil. It is thus possible to use these approaches simultaneously and look for the salinity $S_{1}$, for which the two methods give the same transport through the archipelago. In this manner we may determine both the mass flux and the salinity to use for the upper layers of the Beaufort Sea.

By looking at the different curves (Figs. 7, 9,

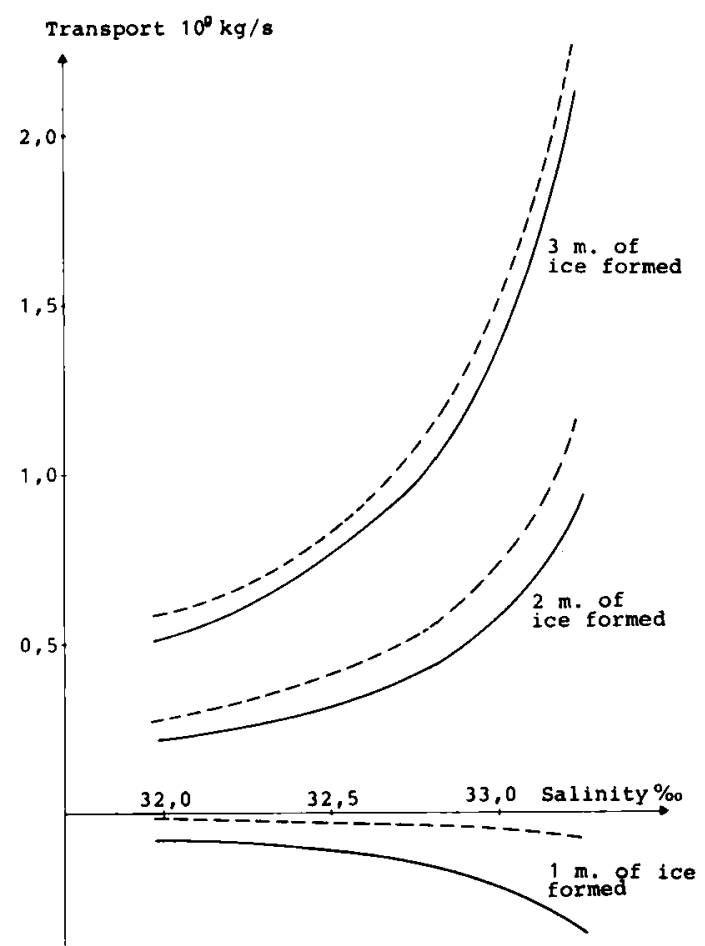

Fig. 10. The transport $M_{1}$ through the Arctic Archipelago as a function of the salinity in the Beaufort Sea. (Broken lines as in Fig. 6.) 
10 ), we have decided upon a value $S_{1}=32.9$ which gives a transport of about $0.7 \cdot 10^{9} \mathrm{~kg}$ $\mathrm{s}^{-1}$ through the archipelago. While these values represent what we believe are acceptable estimates we do not, in view of all approximations being made, consider it to be the last word in the matter. Should the salinity of the ice be put to 3 instead of 5 ? Is the temperature of the cold core -1.6 or $-1.8^{\circ} \mathrm{C}$ ? How representative are the values chosen for the West Greenland Current? What about the assumed heat loss? Some of these questions can be answered by a more extensive search into the literature or by additional and better observations. Still, Baffin Bay is quite a small sea and soon interannual variations may prevent us from reaching further. However, we regard our approach useful in limiting the possible ranges of the mass transport and the salinity of the outflow. In our opinion the transport cannot be less than $0.5 .10^{9} \mathrm{~kg} \mathrm{~s}^{-1}$, and it is unlikely that it is greater than $1.0-1.2 .10^{9} \mathrm{~kg} \mathrm{~s}^{-1}$.

With $S_{1}=32.9$ and $M_{1}=0.7 \cdot 10^{9} \mathrm{~kg} \mathrm{~s}^{-1}$ we find from Figs. 9, 10 that the ice production is slightly above $2 \mathrm{~m}$, and the size of the inflow in the West Greenland Current is also about $0.7 \cdot 10^{9} \mathrm{~kg} \mathrm{~s}^{-1}$, or about $60 \%$ higher than the value used in section 2 . We have, therefore, computed the transport $M_{1}$ resulting from higher value of $M_{g}\left(0.6 .10^{9} \mathrm{~kg} \mathrm{~s}^{-1}\right)$. The results are also shown in Figs. 6, 7. The influence of the West Greenland Current on the outflow is seen to be rather limited.

The mass transports through the Davis Strait are lower but close to the values given by Kiilerich (1939) and Smith et al. (1937). A net ice production of $2.2 \mathrm{~m}$ gives an ice export out of Baffin Bay of $970 \mathrm{~km}^{3} /$ year or $0.03 .10^{9} \mathrm{~kg} \mathrm{~s}^{-1}$, which is almost twice the $500 \mathrm{~km}^{3} /$ year given by Vowinckel \& Orvig (1970).

\section{The interaction between the cold core and the underlying water}

We have assumed that the vertical extent of the winter convection is limited to the upper $200 \mathrm{~m}$ (the cold core). Some locally formed dense water may, however, penetrate deeper into the water mass, and Redfield \& Friedman (1969) suggest on the basis of deuterium measurements that evidence of convection down to $450 \mathrm{~m}$ exists. We shall return to the isotope measurements below (section 5) when we discuss the circulation in the deeper layers.
The entrainment and mixing of water from below into the cold core have so far been ignored. Some interaction must undoubtedly occur, since the temperature in the core is $-1.6^{\circ}$ rather than the freezing-point temperature $-1.8^{\circ}$. Whether this temperature increase is due to turbulent entrainment driven by the energy input through the sea surface, or if molecular processes such as double-diffusive convection are responsible cannot be decided from available data. We shall, therefore, study the possible contributions from entrainment and double-diffusive convection separately to determine whether they are large enough to explain the observed temperature increase.

Stigebrandt (1981) has suggested the following expression for the entrainment velocity

$w_{e}=\frac{2 m_{0} \rho U_{*}^{3}}{g\left(\rho_{0}-\rho_{2}\right) H_{2}}-\frac{\varepsilon Q_{f} \rho_{2}}{A\left(\rho_{0}-\rho_{2}\right)}$

where $m_{0}=1.25$ is a constant. $Q$ represents the buoyancy contribution to the upper layer. $\varepsilon$ is another constant, which is 1 if $Q_{f}>0$ and 0.05 if $Q_{f}<0 . \quad U_{*}=0.55 \mathrm{~cm} \mathrm{~s}^{-1}$ from Stigebrandt (1981). The other symbols have their earlier meanings.

In the present case the positive buoyancy from the inflowing waters and the negative buoyancy from the loss of heat cancel out when the cold core is formed, i.e. the second term vanishes. Taking $H_{2}=200 \mathrm{~m}$ from observations we obtain that $w_{e}=0.42 \cdot 10^{-4} \mathrm{~cm} \mathrm{~s}^{-1} \mathrm{~m}^{-2}$, and if entrainment occurs over the entire area the entrained volume becomes $0.12 .10^{9} \mathrm{~kg} \mathrm{~s}^{-1}$. Using the $H_{2}=$ $300 \mathrm{~m}$ which is needed to export enough water south through the Davis Strait (Table 5, Fig. 10), a correspondingly smaller entrainment results. A thickness of $300 \mathrm{~m}$ of the cold core is observed in the Davis Strait (Defant 1961), but $200 \mathrm{~m}$ seems to be more representative for the whole area (Riis-Carstensen 1936, see also Fig. 2).

In any case, the entrainment appears to be high and the heat-transport resulting from this transfer of warm water is large enough to increase the temperature in the upper layer to $-1.55^{\circ} \mathrm{C}$. This is acceptable, but it is perhaps too simplistic to use a friction velocity approach this deep in the water column, where we rather should expect the activity of internal mechanisms related to interfacial shears and internal waves such as the Kelvin-Helmholz instability to be important. 
Table 5. Mass, heat and salt transports through the Arctic Archipelago: Some estimates. Negative flux: Out of the Polar Ocean. Heat flux relative to $0^{\circ} \mathrm{C}$.

\begin{tabular}{lllll}
\hline Investigator & Mass tr. & Heat tr. & Temp. & Salt tr. \\
\hline & $10^{9} \mathrm{~kg} \mathrm{~s}^{-1}$ & $10^{9} \mathrm{kcal} \mathrm{s}^{-1}$ & ${ }^{\circ} \mathrm{C}$ & $10^{6} \mathrm{~kg} \mathrm{~s}^{-1}$ \\
Vowinckel \& & & & & \\
$\quad$ Orvig 1961 & -1.2 & 0.84 & -0.7 & \\
Mosby 1962 & -1.1 & 2.00 & -1.8 & \\
Timofeyev 1963 & -1.3 & & & \\
Fletcher 1965 & -1.3 & & & \\
Aagaard \& & & 1.50 & -0.7 & -71.8 \\
$\quad$ Greisman 1975 & -2.1 & 2.80 & -1.4 & -67.4 \\
Stigebrandt 1981 & -2.0 & 0.70 & -1.0 & -23.03 \\
Present work & -0.7 & 0.15 & -0.5 & -10.29 \\
Surface water & -0.3 & 0.85 & & -33.30 \\
Deep exchange & -1.0 & & & 33.7 \\
Total & & & & \\
\hline
\end{tabular}

In the transport estimates made in sections 2 and 3 we have used this value for the entrainment, or put it equal to zero. When no entrainment is present the temperature $\theta_{2}$ in section 3 is $-1.8^{\circ} \mathrm{C}$ rather than $-1.6^{\circ} \mathrm{C}$ since this is the temperature when ice is formed and cold core water is created at the surface. The observed temperature increase could be the result of double-diffusive convection (see below). The effect of entrainment on the transports calculations is shown in Tables 3,4 and Figs. 6, 9, 10 .

The overall temperature and salinity structure encountered in the upper layers of Baffin Bay, cold and fresh above warm and saline water, is favourable for diffusive interfaces to form. The present author has, however, no knowledge of whether interfaces have actually been observed in Baffin Bay. They have been found in the Polar Ocean and in the Weddell Sea (Neshyba et al. 1971; Foster \& Carmack 1976) where the conditions are similar. The double-diffusively driven heat transport is dependent upon the magnitude of the temperature steps, and in the absence of observations we have to make some guesses. Assuming that $10-15$ steps are present between the cold core and the underlying warmer layer, an average temperature step of $0.2^{\circ} \mathrm{C}$ is obtained. This is larger than the steps observed in the Arctic (Neshyba et al. 1971), but these steps are found deep in the pycnocline, while steps observed closer to an active convection layer tend to be larger (Foster \& Carmack 1976). Making allowance for intervals with smoother gradients we have chosen the value $0.1^{\circ} \mathrm{C}$ between these two extremes. The overall density ratio $R_{\rho}=\beta \Delta S_{0} / \alpha \Delta T_{0}$ is taken to hold for each step and the expression

$$
F=0.32\left(\kappa_{T}\right)^{2 / 3}\left(\frac{\alpha g}{\nu}\right)^{1 / 3}(\Delta \theta)^{4 / 3}\left(R_{\rho}\right)^{-2}
$$

proposed by Huppert (1971) is used to estimate the vertical heat-transport $F$. In this expression, based upon laboratory measurements made by Turner (1965), $\kappa_{T}$ is the kinematic coefficient of heat diffusion, $\nu$ is the coefficient of viscosity and $\alpha$ and $\beta$ are the coefficients of thermal expansion and salinity contraction, respectively.

With $\kappa_{T}=0.001 \mathrm{~cm}^{2} \mathrm{~s}^{-1}, \alpha=8 \cdot 10^{-5}{ }^{\circ} \mathrm{C}^{-1}, \beta=$ $80.10^{-5}, \nu=0.015 \mathrm{~cm}^{2} \mathrm{~s}^{-1}$ and the observed temperature and salinity ranges from $-1.6^{\circ}$ to $1.0^{\circ} \mathrm{C}$ and from 33.7 to $34.5 ; R_{\rho}$ is 3.1 and the heat transport becomes $F=27.10^{-6} \mathrm{cal} \mathrm{cm}^{-2} \mathrm{~s}^{-1}$. The total heat transport from the lower into the upper layer is then $0.12 \cdot 10^{9} \mathrm{kcal} \mathrm{s}^{-1}$. Since approximately $1.2-1.5 .10^{9} \mathrm{~kg} \mathrm{~s}^{-1}$ is transformed into cold core water, this heat is sufficient to raise the temperature in the cold core by about $0.1^{\circ} \mathrm{C}$ which is somewhat lower than what is observed, but of the same order of magnitude. The corresponding increase in salinity would be a negligible 0.01 .

The double-diffusive process will not cause any water to be transferred between the layers, and the transport estimates obtained, with no entrainment, will not be altered by this process.

It is not possible to decide on the basis of available observations which mechanism is the more important of the two. To be able to do so, 
an externally given initial salinity for the cold core, comparable to the freezing point temperature would be required. Then it might be possible to determine the ratio of heat and salt fluxes and decide whether they represent a linear mixing line or not. However, if the observations reveal the existence of several diffusive layers, we may assume that double diffusive convection is important and that the turbulent entrainment driven by mechanical mixing is not strong enough to disrupt these surfaces.

\section{The deeper layers in Baffin Bay}

The $\theta-S$ structure of the layers beneath the cold core indicates influences both from the Labrador Sea and from the Polar Ocean. Our main objective is to determine the contributions from the north. We must, therefore, assess the transport of water which is denser than the cold core through the archipelago. It must be admitted though, that no conclusive result has been obtained and that our estimate is really a guess. We have made the overall assumption that the driving mechanism for the outflow from the Polar Ocean is the net buoyancy added to the surface layer by the positive fresh water balance in the Arctic. This driving force decreases with depth and the flow vanishes. Due to the sills surrounding Baffin Bay the pressure gradient reverses once more, but at such a deep level that the inflow is obstructed by the sills. Thus, we consider it reasonable to assume that the transport of denser water cannot be larger than the surface transport, and we will tentatively put its value to less than half of the surface transport, or $0.3 .10^{9} \mathrm{~kg} \mathrm{~s}^{-1}$. The temperature and salinity of this water are taken to average $-0.5^{\circ} \mathrm{C}$ and 34.3 respectively.

For the sake of completeness we will examine the circulation of the deeper layers at some length, since this is of interest in its own right. This exercise does not give any absolute magnitudes of the different contributions, and we have chosen to present our preferred estimate directly, rather than have some readers believe that it will emerge from the following discussion. For a more detailed treatment the reader is referred to Muench (1971).

Below the cold core a layer of higher temperature is found. The temperature maximum is located at approximately $500 \mathrm{~m}$ and the temperature $\theta_{0}>1.0^{\circ} \mathrm{C}$ shows influence of Atlantic inflow from the south. This water enters Baffin
Bay in the lower parts of the West Greenland Current and experiences a rapid temperature decrease as it moves along the Greenland coast to the northern parts of Baffin Bay (see $\theta-S$ diagram in Fig. 12).

This lowering of the temperature is most likely the result of isopycnal mixing with water masses already present in Baffin Bay. A surface driven mixing would entrain warm water into the upper layer but not lower the temperature in the lower layer. Penetrative convection could bring cold, perhaps overshooting elements into the underlying water where they would be capable of lowering its temperature, especially since the ineffectiveness of penetrative convection to lift dense water from the lower into the upper layer is well documented (Farmer 1975). However, this implies that a volume of cold water, comparable to the inflow of warm Atlantic water through the Davis Strait, would be convected into the warm layer by surface cooling and ice formation. This is unlikely.

On the other hand, if an extensive recirculation of the lower (warmer) layer exists close to the Davis Strait, as has been suggested by Smith et al. (1937), the rapid decrease in temperature could be the result of mixing between newly entered Atlantic and recirculated water. The $\theta-S$ characteristics observed in the northwestern part of Baffin Bay (Fig. 11) can be taken as representative of this recirculating water, and a mixing ratio of one part from the Davis Strait and four parts of recirculating water would bring about the observed lowering in temperature. The further reduction in temperature which occurs between the northeastern and northwestern parts of Baffin Bay could then result from mixing between equal amounts of water from the northeast of Baffin Bay and from the Polar Ocean, probably entering through the Nares Strait and Jones Sound. The water then exits through the Davis Strait except for the strong recirculation of $2 / 5$ of the volume as was mentioned above.

The 'Atlantic' layer would then consist of $1 / 6$ of water from the south and $5 / 6$ of water from the Arctic. This dominance of water of polar origin in the warm layer is rather surprising. But it is not contradicted by the tracer studies such as the $O^{18} / O^{16}$ measurements reported by Tan \& Strain (1981) which show a close correspondence between $\delta-O^{18}$ values in the 'Atlantic' layer in Baffin Bay and the water found beneath $250 \mathrm{~m}$ in the Nares Strait. 
Fig. 11. $\theta-S$ diagrams showing the observed $\theta-S$ relationship in different localities in Baffin Bay and in the Arctic Archipelago (from Muench 1971).

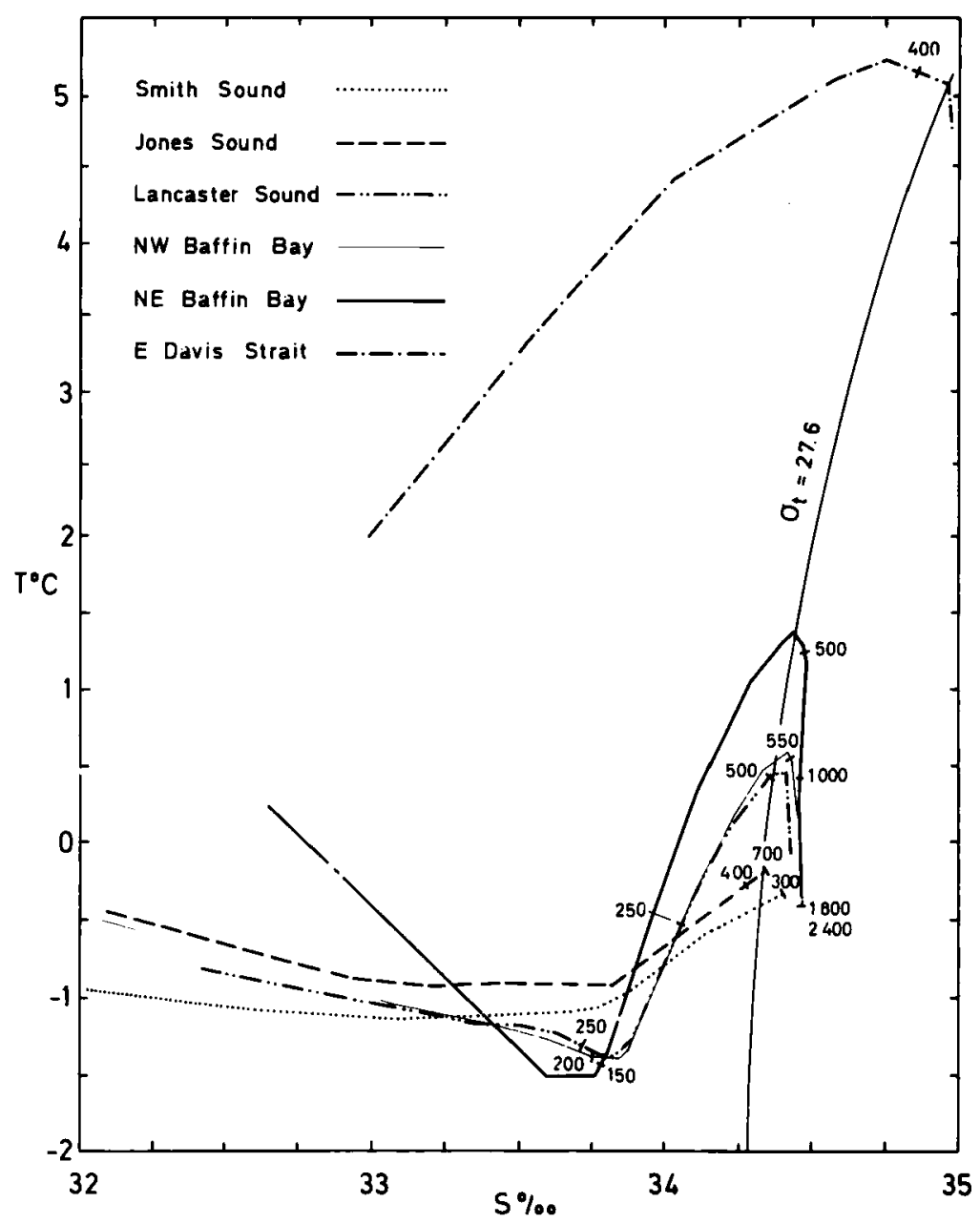

The contribution from the Polar Ocean to the water column in Baffin Bay increases from about $50 \%$ in the surface layer to more than $80 \%$ in the 'Atlantic' layer. The present author is of the opinion that this polar influence becomes even greater at larger depths and accepts the conclusion reached by Bailey (1956) that the deep and bottom water enter from the Polar Ocean, presumably through the Nares Strait. The alternative explanation of the origin of the bottom water that it is formed by mixing water from the Labrador Sea with cooled and brine enriched surface water from Baffin Bay - would require a too vigorous convection.

However, Redfield \& Friedman (1969) have argued, supported by deuterium measurements, that evidence exists of brine enrichment in the Baffin Bay bottom water. Their results are cor- roborated by the $O^{18} / O^{16}$ measurements by Tan \& Strain (1981). We shall comment briefly upon these tracer observations.

The $O^{18}$ and deuterium contents of the assumed fresh water component at the end of a mixingline between fresh- and ocean water depend upon the isotope content in the precipitation which is a function of latitude. The higher the latitude the lighter the precipitation. In general the fresh water component in the Arctic is lighter than the one in the north Atlantic. In addition, a seemingly light isotope mixture may result from ice formation, which does not fractionate the isotopes but increases the salinity of the water. A water parcel will then move horizontally in a $\delta-O^{18}-S$ diagram. A light isotope mixture may then be taken as evidence of ice formation and perhaps convection. However, the expected ice formation 


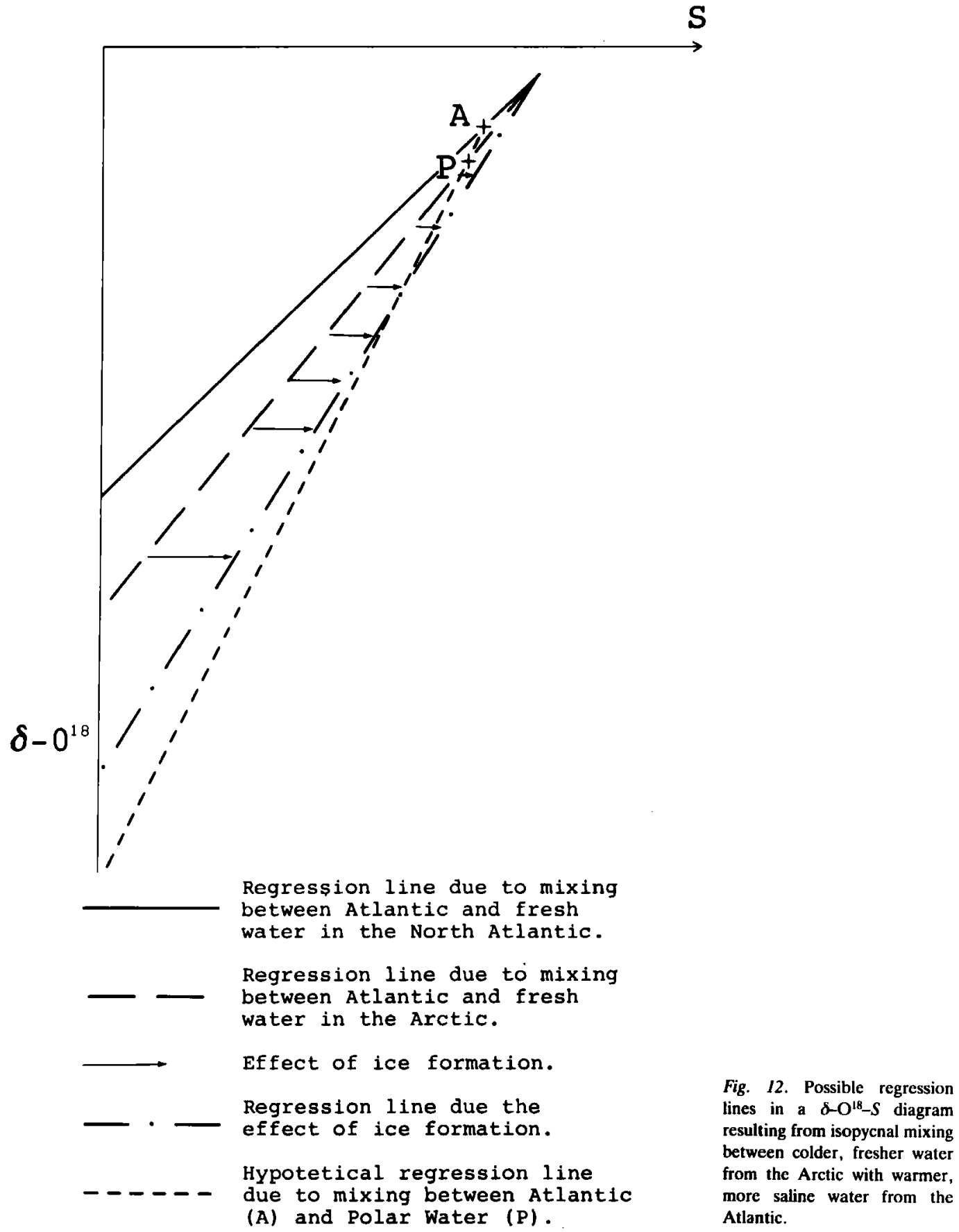

need not to have occurred in Baffin Bay, but may have happened earlier in the flow history of the water, perhaps in the Bering Sea and on the Chukchi shelves, since the salinity of the deep layers in Baffin Bay is close to the one sometimes observed for the Bering Sea winter water. The higher temperature could be the result of interaction, perhaps through double-diffusive convection with the Atlantic layer in the Polar Ocean. 
rejection, for creating a seemingly light isotope mixture in the fresh water component. Consider two parcels, one from the Arctic, the other from the Atlantic. The isotope mixtures of their fresh water components are different. If these two waters are mixed isopycnally, the arctic water being somewhat colder and fresher, then the apparent fresh water component for the resulting water mass as found from the $\delta-O^{18}-S$ diagram is lighter than those found in either of the original water masses (Fig. 12).

The light fresh water component found in the deep and bottom water of Baffin Bay could then be the result of mixing of Atlantic and polar waters rather than the effect of deep convection in Baffin Bay. We only mention this as an example of the ambiguities which are connected with the interpretation of isotope and tracer measurements.

\section{Summary: The Arctic Archipelago}

The transports through the Arctic Archipelago are in the surface layer, $0.7 .10^{9} \mathrm{~kg} \mathrm{~s}^{-1}$ with temperature $-1.0^{\circ} \mathrm{C}$ and salinity 32.9 , and in the deeper layers, $0.3 \cdot 10^{9} \mathrm{~kg} \mathrm{~s}^{-1}$ with temperature $-0.5^{\circ} \mathrm{C}$ and salinity 34.3 (see Table 5). The transports estimates are rather low with respect to mass as well as salt (see Table 5), especially when compared to the more recent estimates.

The residence times for the water in the cold core and in the warmer layer are found to be about 2 and 20 years respectively, a sufficient time for the surface layer to experience one winter cooling and attain the characteristic cold core temperature and salinity. The residence times are in rough agreement with the age of the waters in the two layers, which is found by Top et al. (1980) from $\mathrm{He}^{4} / \mathrm{He}^{3}$ measurements $(2$ and 8 years respectively), provided that age and residence time are equivalent concepts. Top et al. also estimated from oxygen consumption the ventilation of the bottom water. They found a residence time of $500-1000$ years. This would require a transport of less than $0.01 .10^{9} \mathrm{~kg} \mathrm{~s}^{-1}$ of water from the Polar Ocean into Baffin Bay with the characteristic $\theta=-0.4^{\circ} \mathrm{C}, S=34.5$. Such a flow would be feeble enough to escape detection.

It should not be necessary to point out that the present work is highly idealized and that many processes and local variations have been ignored (Muench 1971). We can only hope that the more important ones have been retained.
Acknowledgements. - The author is grateful to Professor Gösta Walin for suggesting work on the Arctic Archipelago, and for his encouragement and criticism along the way, and to Professor Knut Aagaard for a thorough reading of an early draft. Thanks are also due to Mrs. Jorunn Myklebust for her typing of the manuscript.

\section{References}

Aagaard, K. \& Greisman, P. 1975: Towards new mass and heat budgets for the Arctic Ocean. J. of Geophys. Res. 80, 38213827 .

Bailey, W. D. 1956: On the origin of Baffin Bay deep water. J. of Fish. Res. Bd. of Canada 13(3), 303-308.

Bailey, W. D. 1957: Oceanographic features of the Canadian Archipelago. J. of Fish. Res. Bd. of Canada 14, 731-769.

Coachman, L. K. \& Aagaard, K. 1966: On the water exchanges through Bering Strait. Limnol. and Oceanogr. 11, 44-59.

Coachman, L. K. \& Aagaard, K. 1974: Physical oceanography of the arctic and subarctic seas. Pp. 1-72 in Herman, Y. (ed.): Marine geology and oceanography of the arctic seas. SpringerVerlag, New York.

Collin, A. E. \& Dunbar, M. J. 1963: Physical oceanography in Arctic Canada. Pp. 45-77 in Barnes, H. E. (ed.): Oceanography and biology, annual review 2.

Defant, A. 1961: Physical Oceanography 2. Pergamon Press, London.

Fletcher, J. O. 1965: The Heat Budget of the Arctic Basin and its relation to Climate Santa Monica, California. The Rand Corporation, R-444-PR. $179 \mathrm{pp}$.

Farmer, D. M. 1975: Penetrative convection in the absence of mean shear. Quart. Journ. of the Royal Met. Soc. 101, 869 891.

Foster, T. D. \& Carmack, E. C. 1976: Temperature and salinity structure in the Weddell Sea. Deep-Sea Res. 23, 301-317.

Huppert, H. E. 1971: On the stability of a series of doublediffusive layers. Deep-Sea Res. 18, 1005-1021.

Kiilerich, A. B. 1939: The 'Godthaab' expedition 1928: A theoretical treatment of the hydrographical observational material. Meddelelser om Gronland.

Mosby, H. 1962: Water, mass and heat balance of the North Polar Sea and of the Norwegian Sea. Geof. Publ. 24(11), 289-313.

Muench, R. 1971: The physical oceanography of the Northern Baffin Bay region. The Baffin Bay - North Water project. Scientific report No. 1. Arctic Institute of North America. 150 pp.

Neshyba, S., Neal, V. T. \& Denner, W. 1971: Temperature and conductivity measurements under ice island T-3. J. of Geophysical Res. 76, 8107-8120.

Redfield, A. C. \& Friedman, 1. 1969: The effect of meteoric water, melt water and brine on the composition of Polar Sea Water and of deep water in the ocean. Deep Sea Res. 16, 197-214.

Riis-Carstensen, E. 1936: The 'Godthaab' expedition 1928: The hydrographic work and material. Meddelelser om Grønland 78(3). $101 \mathrm{pp}$

Sadler, H. E. 1976: Water, heat and salt transports through Nares Strait, Ellesmere Island. J. Fish. Res. Bd. of Canada 33(10), 2286-2295.

Smith, E. H., Soule, F. M. \& Mosby, O. 1937: The 'Marion' expedition to Davis Strait and Baffin Bay: Part II. Physical oceanography, United States Coast Guard Bull. 259 pp. 
Stigebrandt, A. 1981: A model for the thickness and salinity of the upper layer of the Arctic Ocean and the relationship between the ice thickness and some external parameters. $J$. of Phys. Oceanogr. 11, 1407-1422.

Sverdrup, H. V., Johnson, M. W. \& Fleming, R. M. 1942: The Oceans, their Physics, Chemistry and General Biology. Prentice-Hall, Englewood Cliff. NJ. 1087 pp.

Tan, F. C. \& Strain, P. M. 1981: The distribution of sea-ice melt water in the eastern Canadian Arctic. J. of Geophys. Res. 85, 1925-1932.

Tchernia, P. 1979: Descriptive Regional Oceanography. Pergamon Press, Oxford. $253 \mathrm{pp}$.

Timofeyev, V. T. 1963: Interaction of waters from the Arctic Ocean with those from the Atlantic and Pacific (trans.). Okeanologiya 3(4), 569-578.
Top, Z., Clarke, W. B., Eismont, W. C. \& Jones, E. P. 1980: Radiogenic helium in Baffin Bay bottom water. J. of Marine Research 38(3), 435-452.

Turner, J. S. 1965: The coupled turbulent transports of salt and heat across a sharp density interface. Int. J. Heat and Mass Transp. 8, 759-767.

Vowinckel, E. \& Orvig, S. 1961: Water balance and heat flux of the Arctic Ocean. McGill University publications in Meteorology $44.35 \mathrm{pp}$.

Vowinckel, E. \& Orvig, S. 1970: The climate of the North Polar Basin. Pp. 370 in Orvig, S. (ed.): Climates of the polar regions. World climate survey vol. 14. Elsevier Publishing Company. 